\title{
An Overview of Oxygen Reduction Electrocatalysts for Rechargeable Zinc-Air Batteries Enabled by Carbon and Carbon Composites
}

Junkai Zhao, ${ }^{1,2}$ Daina Wei, ${ }^{1,2}$ Ce Zhang, ${ }^{2, *}$ Qian Shao, ${ }^{3}$ Vignesh Murugadoss, ${ }^{4}$ Zhanhu Guo, ${ }^{5, *}$ Qinglong Jiang 6 and Xiaojing Yang ${ }^{1, *}$

\begin{abstract}
The merits, such as high specific capacity, less self-discharge and high storage life, make Zinc (Zn)-air batteries promising to serve as energy storage and conversion equipment to effectively solve the energy crisis and environmental pollution caused by the rapid increasing global energy consumption, especially the use of fossil energy. However, the applications and further deployments of the $\mathrm{Zn}$-air batteries depend on costly noble metal as cathodes and are limited by sluggish electrochemical reaction kinetics. As one of the competitive alternatives to noble metals, carbon-based materials such as metal/carbon, nonmetal atom/carbon, metal oxide/carbon and metal-metal oxide-heteroatom/carbon materials exhibit the advantages of structural diversity, high porosity, excellent volume conversion efficiency and non-toxicity. With the emphases on structural improvement and composition optimization, this article summarizes the advances in the development of oxygen reduction reaction (ORR) electrocatalyst based on various carbon contained composites for $\mathrm{Zn}$-air battery cathodes. Furthermore, the challenges and perspectives of the research directions on the $\mathrm{Zn}$-air battery with carbon contained composites as catalyst are discussed in detail.
\end{abstract}

Keywords: Oxygen Reduction; Electrocatalysts; Zn-Air Battery; Carbon; Carbon Composites.

Received: 22 November 2020; Accepted: 3 February 2021.

Article type: Review article.

\section{Introduction}

As science and technology bring the convenience and benefits to modern society, the potential dangers of resource shortage and environmental pollution also arise gradually. In order to

${ }^{1}$ Beijing Key Laboratory of Energy Conversion and Storage Materials, College of Chemistry, Beijing Normal University, Beijing 100875 China.

${ }^{2}$ Qian Xuesen Laboratory of Space Technology, China Academy of Space Technology (CAST), Beijing 100094 China.

${ }^{3}$ College of Chemical and Environmental Engineering, Shandong University of Science and Technology, Qingdao 266590 China.

4 Advanced Materials Division, Engineered Multifunctional Composites (EMC) Nanotech LLC, Knoxville, TN 37934 USA.

${ }^{5}$ Integrated Composites Laboratory (ICL), Department of Chemical \& Biomolecular Engineering, University of Tennessee, Knoxville, TN 37996 USA.

${ }^{6}$ Department of Chemistry and Physics, University of Arkansas, Pine Bluff, AR 71601, USA.

*E-mail: zhangce@qxslab.cn (C. Zhang); zguo10@utk.edu (Z. Guo) and yang.xiaojing@bnu.edu.cn (X. Yang) avoid the greenhouse gas emissions, it is necessary and urgent to explore clean and renewable energy for reducing the consumption of fossil fuels. ${ }^{[1-5]}$ Thus, the application of sustainable energy is extraordinarily meaningful for alleviating the natural resource shortage and environmental crisis. Various advanced energy storage devices, such as metal-air batteries, fuel cells, supercapacitors, water-splitting for hydrogen generation, redox flow batteries and so on, are considered to play an irreplaceable role. ${ }^{[6-8]}$ The everincreasing requirement of energy supply, coupled with the limited capacity of energy storage equipment, have motivated the search for electrochemical energy storage devices with improved safety, longer life time and higher capacity. Among all kinds of energy storage devices, metal-air battery has become one of the most promising candidate for the generation with large-scale hybrid transportation facilities and electric vehicles due to its advantages of ultrahigh energy density, non-toxic, pollution-free and cost effective. ${ }^{[9]}$ Metalair batteries usually use metals with negative electrode potentials (such as zinc, magnesium, aluminum, and iron) as the anode, and oxygen reductive electrode in the air as the 


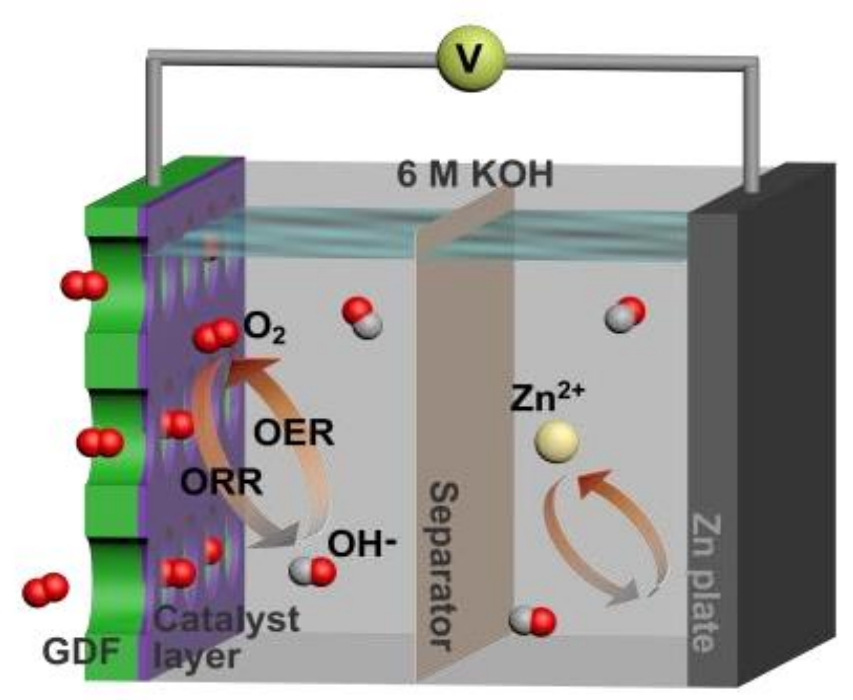

Fig. 1 The schematic of the zinc-air battery model (GDF: gas diffusion film), reproduced with the permission from [11], Copyrights 2019, American Chemical Society. cathode. Compared with various metal-air batteries, Zn-air battery has been widely studied due to the environmental benignity, abundance, and low price of $\mathrm{Zn} .{ }^{[10]} \mathrm{Fig} .1$ shows a typical $\mathrm{Zn}$-air battery model. It can be seen that the structure of the Zn-air battery is simple, mainly including a metal electrode, an air electrode, electrolyte, separator and external circuitry. ${ }^{[11]}$ For the metal-air batteries, no matter what kind of the anode material is the cathodic oxygen reduction reaction (ORR) is essential for the electrochemical processes, and the electrocatalyst performance of the cathode material dominates the comprehensive performance and discharge efficiency of the related battery devices. ${ }^{[12,13]}$ Since the metal-air batteries were proposed in 1878, scholars have never stopped the research on their performance improvement. ${ }^{[14,15]}$ In order to use metal-air batteries in daily electronic equipment and largescale grid systems instead of staying in the laboratory stage, many efforts have been made to meet the requirements of safety, long lifetime, high energy density, economic and environmental protection. Numerous studies have been carried out on battery electrode materials, electrolyte composition and selection of separators. Improving the electrochemical activity

(a)
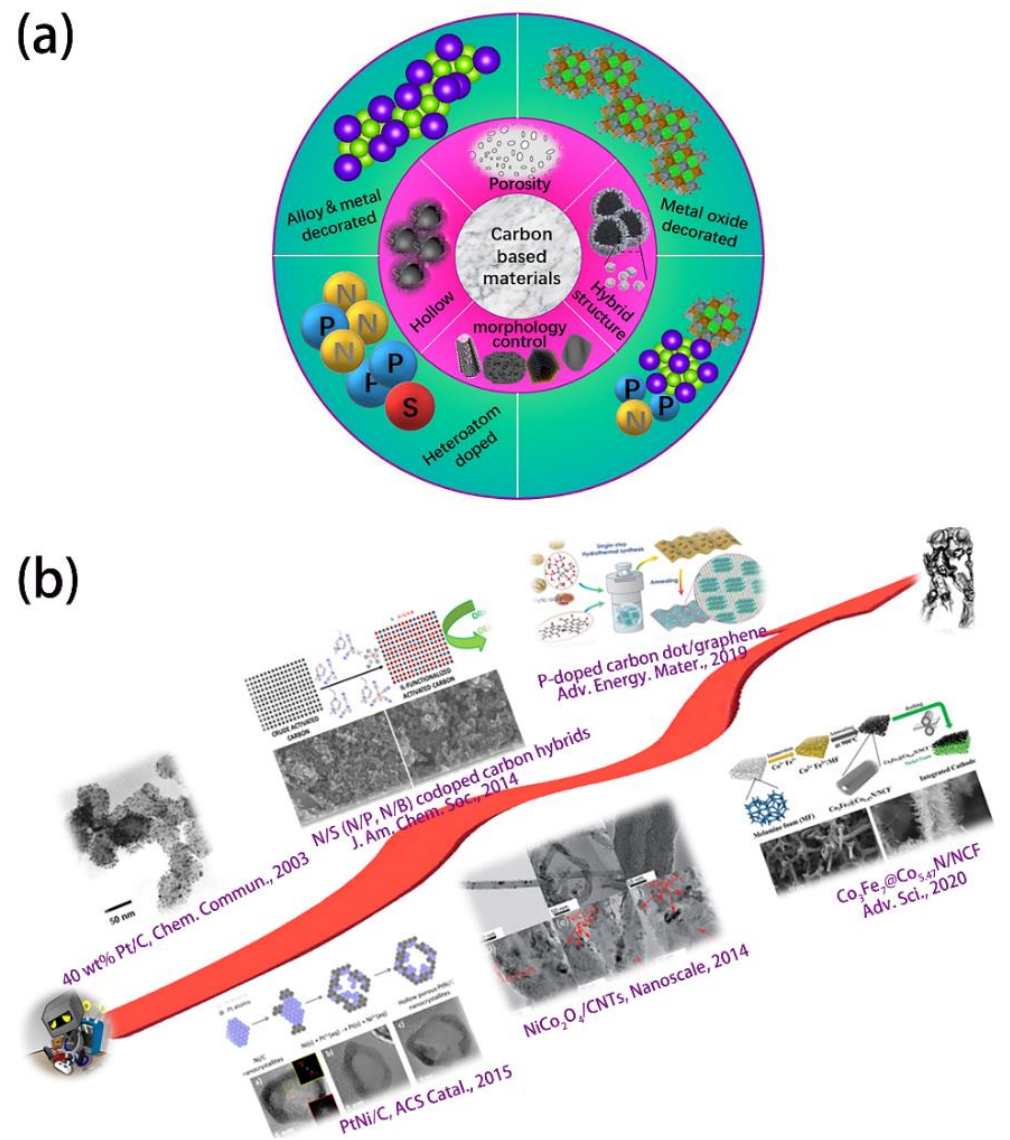

Fig. 2 (a) Various strategies to improve the performance of carbon-based catalysts. (b) different types of the carbon-based ORR catalysts $(40 \mathrm{wt} \% \mathrm{Pt} / \mathrm{C}$, reproduced with the permission from [40], Copyright 2003 The Royal Society of Chemistry 2003, the PtNi/C, reproduced with the permission from [46], Copyrights 2015 American Chemical Society, the $\mathrm{NiCo}_{2} \mathrm{O}_{4} / \mathrm{CNTs}_{\text {, }}$ reproduced with the permission from [46], Copyright 2014The Royal Society of Chemistry, the N, P co-doped carbon, reproduced with the permission from [47], Copyrights 2014 American Chemical Society, the P-doped carbon dot/graphene, reproduced with the permission from [44], Copyright 2019 WILEY-VCH Verlag GmbH \& Co. KGaA, Weinheim, the Fe-Ni and N doped carbon hollow spheres, reproduced with the permission from [48], Copyright 2020 Elsevier Ltd. 
of electrode materials is the most direct and effective approach to improving the battery performance. ${ }^{[16-18]}$ Since most metals will undergo severe corrosion or hydrogen evolution in acid electrolytes, alkaline electrolytes are generally used in metalair battery electrolytes. The reduction reaction of oxygen on the air electrode is usually intricate. In general, the electrode reaction of metal-air batteries can be simplified as Equations (1) and (2): ${ }^{[15,19,20]}$

$$
\begin{gathered}
\text { Metal electrode: } \mathrm{M} \longleftrightarrow M^{\mathrm{n}+}+\mathrm{ne}^{-} \\
\text {Air electrode: } \mathrm{O}_{2}+4 \mathrm{e}^{-} \longleftrightarrow 2 \mathrm{H}_{2} \mathrm{O}+4 \mathrm{OH}^{-}
\end{gathered}
$$

where $\mathrm{M}$ and $\mathrm{n}$ represent the metal $(\mathrm{Zn}, \mathrm{Mg}, \mathrm{Al}$, etc.) of the anode electrode and electron transfer numbers, respectively. Oxygen reduction reaction and oxygen evolution reaction (OER) are the core factors affecting the battery performance, and the sluggish electrochemical reaction kinetics is the main reason hindering the large-scale commercial popularity of the metal-air batteries. ${ }^{[21,22]} \mathrm{It}$ is undeniable that noble metal-based catalysts, such as $\mathrm{Pt}, \mathrm{Ag}$ and $\mathrm{Au}$, have satisfactory catalytic activities for the oxygen reduction, and they have dominated the catalysts for a considerable period. ${ }^{[23,24]}$ However, the reserves of noble metals in nature are rare and expensive, which is difficult to apply to the large-scale energy storage applications. ${ }^{[25,26]}$ Exploring new catalyst to replace the noble metals partially or completely has gradually become the primary option and research hotspot. ${ }^{[27-30]}$

Carbonaceous materials have attracted widespread

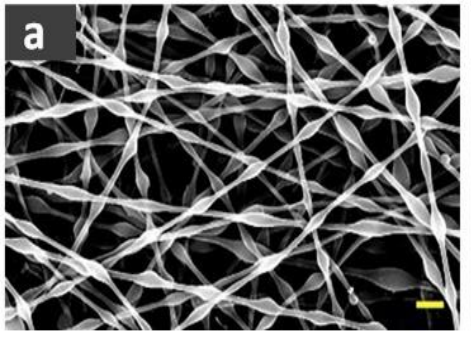

Bamboo

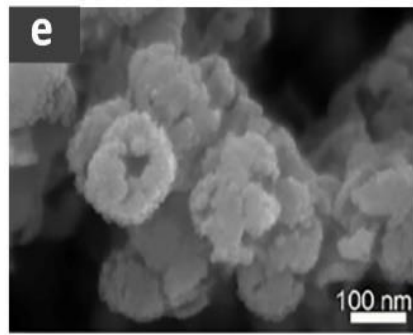

Spheres

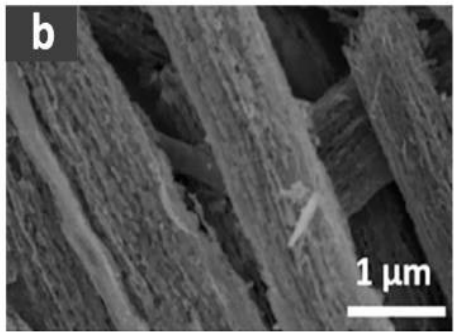

Fibre

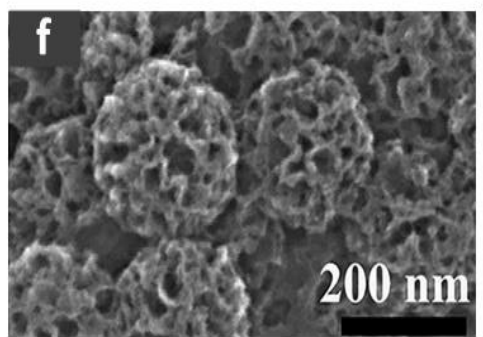

Nanoflowers

attention because of the advantages such as high electronic conductivity, strong toughness, high chemical stability and high specific surface area, and is acclaimed as one of the most promising next generation catalysts to replace the noble metal catalysts. ${ }^{[31-35]}$ Nowadays, various strategies have been exploited for preparing carbon materials doped or incorporated with transition metals, metal oxides nonmetal atoms or their compounds. ${ }^{[36]}$ Previous studies have showed that the content of noble metal $\mathrm{Pt}$ in $\mathrm{Pt} / \mathrm{C}$ electrodes often reaches $60 \%$, and the scarcity of Pt makes it impossible to be widely used. ${ }^{[37]}$ Recent researches suggest that carbon heterogeneous materials composites reveal ideal ORR and OER catalytic activity simultaneously. ${ }^{[38,39]}$ Combining with elements or compounds, such as metal, nonmetal and transition metal oxides, carbon materials could form coordination complex. Fig. 2a summarizes various strategies to improve the performance of the carbon-based catalysts. Fig. $2 \mathrm{~b}$ shows the continuous improvement in the composition and structure of carbon contained ORR catalysts in the past two decades. ${ }^{[40-48]}$ Herein we describes and summarizes the catalytic applications of carbon-based materials, including metal/carbon, nonmetal atom/carbon, metal oxide/carbon and metal-metal oxide-nonmetal atom carbon materials. This review also highlights the research progress, performance differences and development trends of carbon composites with different structures and compositions as the cathode materials for metal-air batteries.
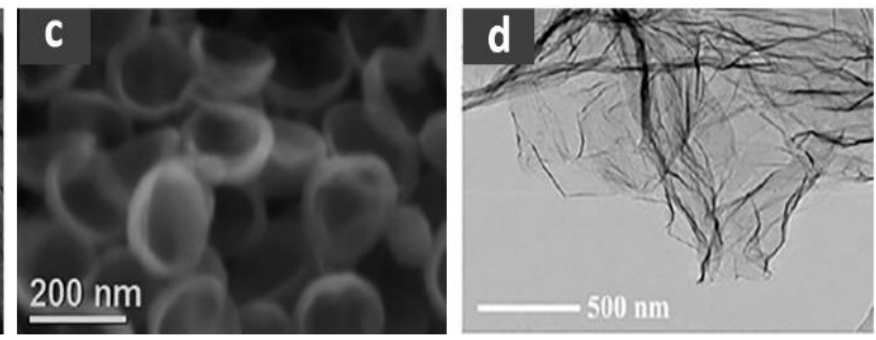

Bowls

Graphene

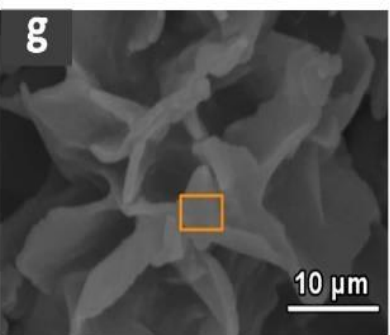

Nanosheets

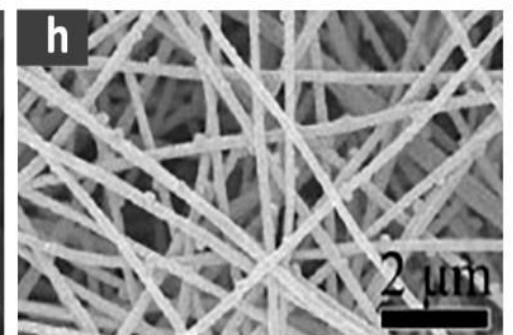

Nanotube

Fig. 3 Carbon composites of various structures, (a) bamboo, reproduced with the permission from [58], Copyright 1999-2019 John Wiley \& Sons, Inc, (b) nanofibers, reproduced with the permission from [60],Copyright 2017 American Chemical Society, (c) nano bowls, reproduced with the permission from [61], Copyright 2019 American Chemical Society, (d) graphene, reproduced with the permission from [62],Copyright 2018 American Chemical Society, (e) nanospheres, reproduced with the permission from [63] Copyright 2018 American Chemical Society, (f) nanoflowers, reproduced with the permission from [54], Copyright The Royal Society of Chemistry 2017, (g) nanosheets, reproduced with the permission from [59],Copyright 2020 American Chemical Society, (h) nanotubes, reproduced with the permission from [64], Copyright 2017 American Chemical Society. 
2. Structure improvement of carbonaceous oxygen reduction catalyst

\subsection{Morphology control}

Structure improvement is an important way to enhance the performance of carbon based catalysts. ${ }^{[49-51]}$ Fig. 3a-h shows a variety of structures of carbonaceous materials, including nanospheres, nanosheets, nanoflowers, nanofibers and nanotubes, etc. ${ }^{[52-64]}$ Compared with traditional bulk materials, the samples with regular morphologies show higher specific surface area, lower agglomeration and greater structural stability, and thus possess practical application values. ${ }^{[65]}$

Generally, the influence of material structures on the electrochemical performance of metal-air batteries are manifold. For example, the ultra-high specific surface area and porosity of the material can ensure excellent dispersion of catalyst and provide more reactive sites, and simultaneously improve the adsorption rate and diffusion permeability of the $\mathrm{O}_{2 .}{ }^{[66]}$ More critically, carbon materials with special morphologies often convey outstanding physical toughness and can maintain structural integrity after thousands of chargedischarge cycles, providing a powerful guarantee of the stability and lifetime of the catalyst.

\subsection{Porosity engineering}

Except carbon nanotubes (hollow tubes) and graphene (2D sheet structure), the structures of conventional carbon composite materials are mainly controlled by synthetic methods ${ }^{[67-69]}$ In addition to morphology control, the porous design is also an important factor to impact the catalytic activity of the carbon-based catalysts. For example, Jiang et al. put forward a spontaneous gas-foaming technique to prepare nitrogen doped porous carbon composites through one-step carbonization process. ${ }^{[70]}$ The selected carbon sources were citric acid and $\mathrm{NH}_{4} \mathrm{Cl}$, and the obtained samples showed distinctive structure at different heat treatment temperatures. The sample achieved at a relatively low temperature of $800^{\circ} \mathrm{C}$ was porous carbon nanosheets, and the cross-linked $3 \mathrm{D}$ porous carbon networks were generated when the carbonization temperature reached $1000{ }^{\circ} \mathrm{C}$. Porosity-rich carbon-based materials obtained from the biomass precursors with unique structures are considered as an effective strategy. Various biomass materials have been selected as the carbon sources, and the morphologies as well as structures of the obtained samples were entirely different. For instance, carbonaceous materials obtained from animal bones and fish scales as carbon sources possessed high-defect mesopore-dominated porous carbon structure and honeycomb-like structure, respectively. ${ }^{[71}$ Numerous studies have shown that utilizing precursors with abundant, wide distribution and low-price resources to synthesize novel carbon-based energy storage materials could be a feasible strategy. ${ }^{[72,73]}$ This strategy undoubtedly paves a unique way to prepare the advanced electrode materials for ORR catalysis.

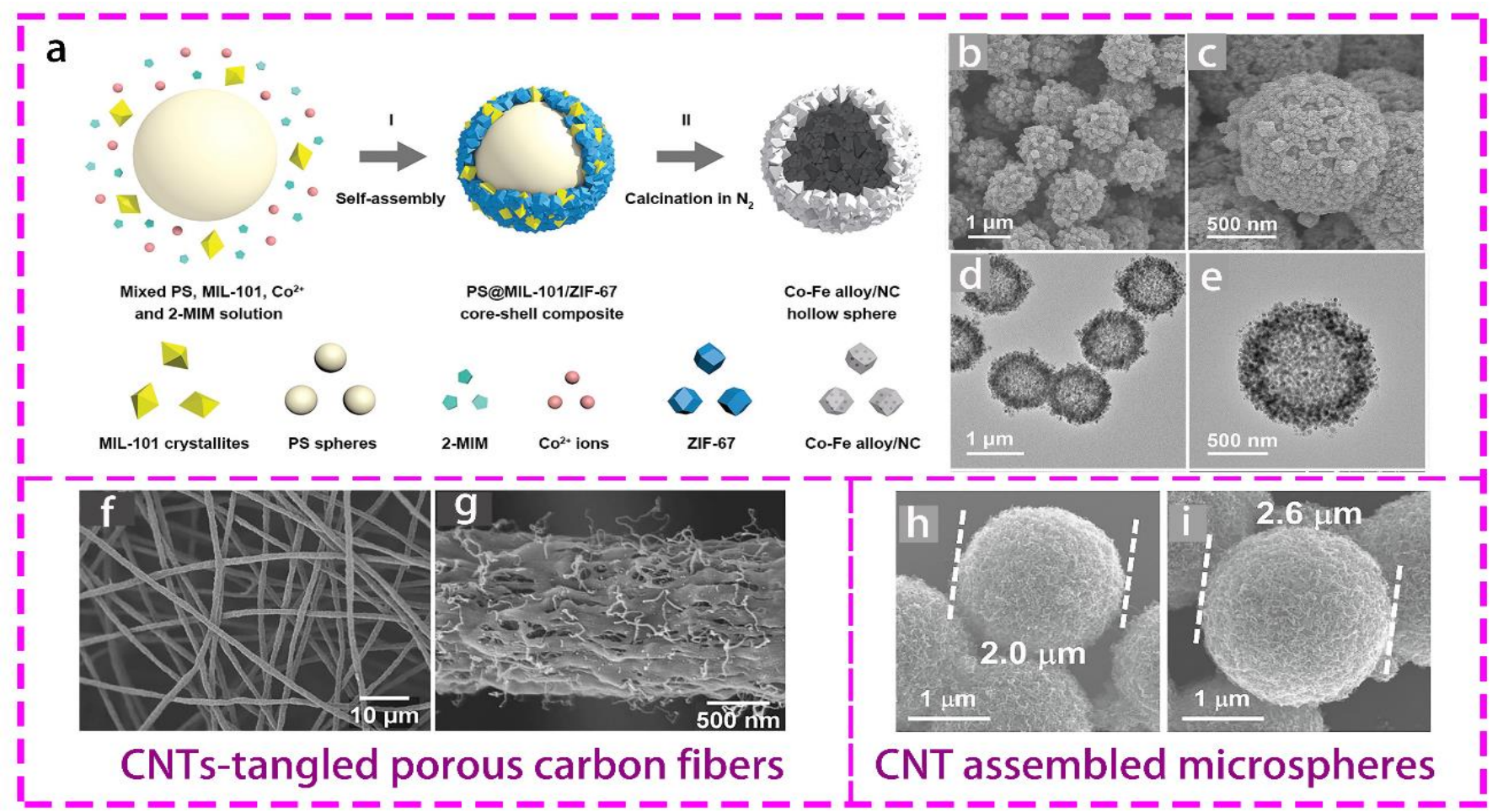

Fig. 4 Samples composed of regular morphology particles. (a) Schematic illustration of the formation process of the Co-Fe alloy/Ndoped carbon hollow spheres. (b, c) SEM images and (d, e) TEM images of the Co-Fe/NC-700 hollow spheres, reproduced with the permission from [85], Copyright 2019 WILEY-VCH Verlag GmbH \& Co. KGaA, (f, g) SEM images of the N-doped CNTs-tangled porous carbon fibers, reproduced with the permission from [87] Copyright (C) 2019 Elsevier B.V., (h, i) SEM images of the Co-N codoped carbon nanotube hollow microsphere, reproduced with the permission from [85] Copyright 2019 Elsevier B.V. 


\subsection{Hybrid structure}

In recent years, novel carbonaceous materials were formed by mixing carbon materials of various structures. Forming composite materials composed of multiple structures to improve the structural stability and catalytic activity supports a new and effective method. ${ }^{[74]}$ The prime purpose of structure combination is to integrate the advantages of various structures, and the most common approach is to combine carbon nanotubes with graphene. The ultra-thin graphene sheets with high specific surface area and intrinsic electron mobility always face the problems of structural collapse and $\pi-\pi$ stacking interactions, leading to their performance in practical applications far below the theoretical expectations. ${ }^{[75,76]}$ Song et al. synthesized nitrogen doped graphene material with CNTs grown on its surface through an easy-to-implement method, and this distinctive structure effectively averted the stacking and agglomeration of graphene sheets. ${ }^{[77]}$ Furthermore, this composite can also increase the density of reactive sites exposed to the outside of the material, and such meticulously designed structure could support a long-term development in the field of electrocatalyst. ${ }^{[78,79]}$

Advanced metal-organic framework (MOF) composites and unique porous hollow structure materials have been extensively employed as nano-catalysts and electrode materials because of the advantages of wide buffer space, high adsorption rate and structural strength. ${ }^{[80-83]}$ Combining metal particle composites derived from the MOF-assisted approach with template method gradually becomes a common way to prepare porous carbon-based catalysts. ${ }^{[84]}$ For example, $\mathrm{Co}-\mathrm{Fe}$ alloy@N/C hollow microspheres with excellent electrochemical performance were successfully prepared by Zhang et al. ${ }^{[85]}$ As shown in Fig. 4a, the synthesized Fe-based MIL-101 nanoparticles and Co-based ZIF-67 nanoparticles were assembled on the surface of monodispersed polystyrene (PS) microspheres template by self-assembly process to form core-shell structure, and then removed the supporting materials and achieved hollow structure electrocatalyst. The well-defined hollow spheres of the products and the shell composed of regular morphology particles can be clearly seen through the SEM and TEM images (Figs. 4b-e). In addition, several studies focused on the combination of special structural units into integrated morphological complexes, as shown in Figs. 4f-i. ${ }^{[86,87]}$ These materials not only exhibited high catalytic activity and excellent electron transfer ability of the conventional carbon-based materials, but also possessed abundant mesopores, sufficient internal void space and high dispersibility. ${ }^{[87]}$

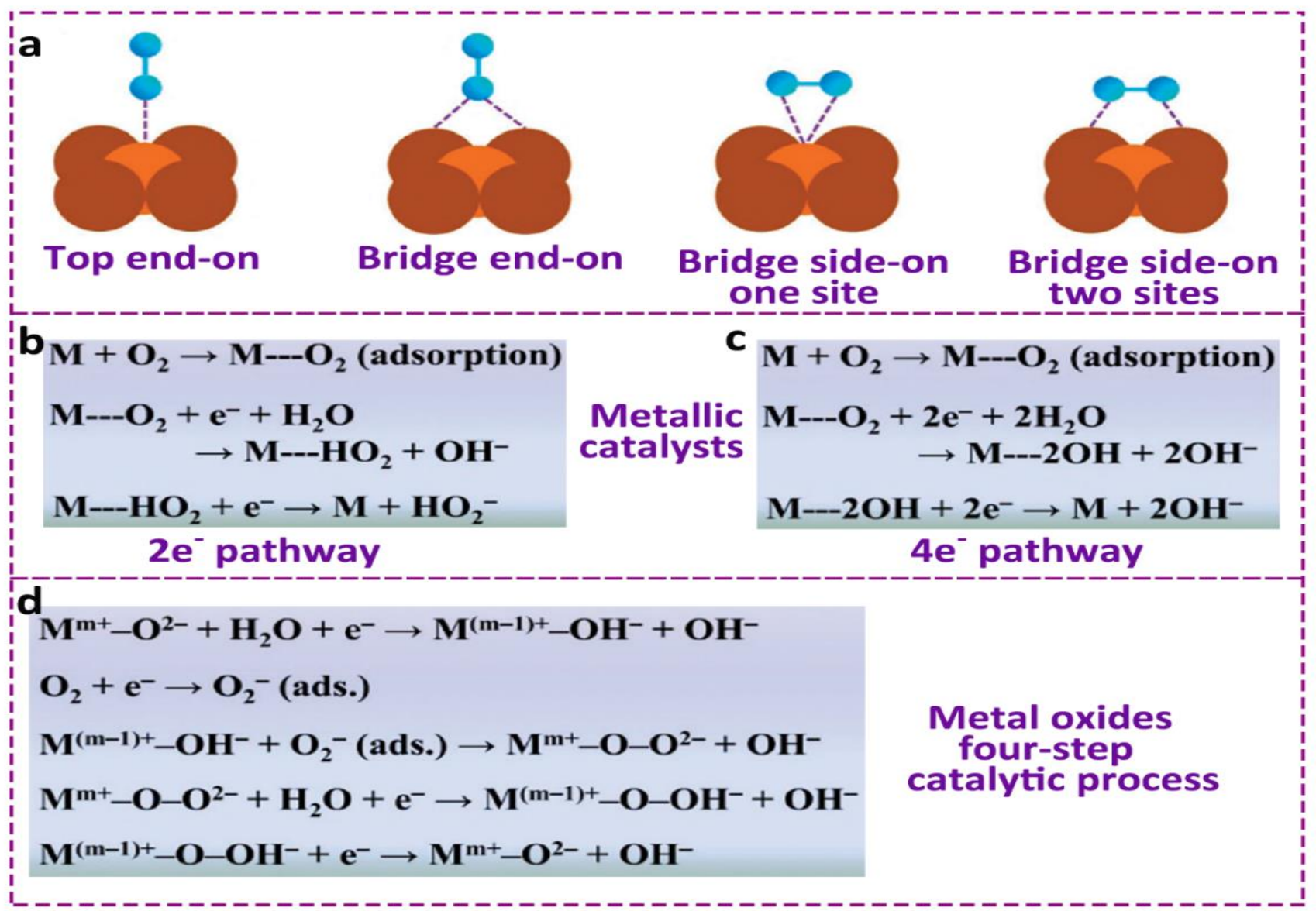

Fig. 5 Catalytic mechanism of different materials. (a) adsorption configuration of catalyst for $\mathrm{O}_{2}$, ORR electrocatalytic process equation of (b, c) metal catalysts and (d) metal oxides catalysts, reproduced with the permission from [90], Copyright 2012 The Royal Society of Chemistry. 


\section{Metal/carbon composite as ORR electrocatalysts}

$\mathrm{Metal} /$ carbon ORR electrocatalyst is developed on the basis of noble metal catalyst. Because the orbits in the outermost layer of noble metals are not filled or not fully filled by electrons, their special electronic arrangement makes them easy to adsorb reactant molecules and forms catalytic active centers. ${ }^{[88,89]}$ Fig. 5 describes the adsorption configurations of ideal catalyst with the oxygen molecule and lists the reaction equations of adsorption processes.

As shown in Figs. 5a-d, although the variety of catalyst materials and different configurations for oxygen adsorptions led to diversified of the ORR process, the main catalytic intermediates were $\mathrm{O}, \mathrm{OH}, \mathrm{O}_{2}^{-}$and $\mathrm{HO}_{2}^{-}{ }^{\left[{ }^{900}\right.}$ Previous studies on noble metal/carbon catalysts and density functional theory (DFT) calculations showed that noble metals such as Pt can break the $\mathrm{O}=\mathrm{O}$ double bonds of oxygen molecules adsorbed on its surface, and the intermediate products can be detached from the catalyst surface subsequently, allowing the reaction proceed continuously. Therefore, the previous research mainly focused on the conventional $\mathrm{Pt} / \mathrm{C}$ catalyst, for example, Zhou et al. prepared the $\mathrm{Pt} / \mathrm{C}$ electrocatalyst with a nanoscale size distribution through a simple modified polyol process and the as-synthesized active substance was superior to commercial catalyst in the ORR tests. ${ }^{[40]}$ The contradiction between the scarcity of noble metals in nature and the heavy demand of the catalysts for social development indicates the popularization of $\mathrm{Pt} / \mathrm{C}$ ORR catalysts may be inappropriate for large-scale application in the near future. As one of the substitutes of the $\mathrm{Pt} / \mathrm{C}$ catalysts, Pt-metal (Pt-M) alloys have been developed and extensively studied. The diameter of the transition metal atoms in the Pt-M ( $\mathrm{M}=\mathrm{Fe}, \mathrm{Co}, \mathrm{Ni}, \mathrm{Ag}, \mathrm{Au}$ etc. $)$ alloy catalyst is smaller than that of the platinum atom and the Pt-Pt atomic spacing in formed alloy is shrank (geometric effect). ${ }^{[91-93]}$ Simultaneously, the transition metals tend to lose electrons and thus change the electronic structure of the alloy surface (electronic effect). The synergistic effect of geometric and electronic effect facilitates the bidentate adsorption of $\mathrm{O}_{2}$ on the catalyst surface and the desorption of reaction products, which further improves the catalytic efficiency. ${ }^{[94,95]}$ In a recent report, Wang et al. prepared three carbon supported low-Pt content oxygen reduction catalysts including $\mathrm{PtFe}_{3}, \mathrm{PtCo}_{3}$ and $\mathrm{PtNi}_{3}$ nanoparticles with high activity and stability. ${ }^{[96]}$ Energydispersive X-ray spectroscopy (EDS) and inductive-coupledplasma atomic emission spectroscopy (ICP-AES) were employed to estimate the element ratio of the prepared samples and it was found that the content ratio of $\mathrm{Pt}$ to other metals in the alloy was about $1: 3$, which was significantly lower than that of previous Pt-based catalyst. ${ }^{[37,97]}$

Replacing Pt with high-reserve, low-refinement transition metals in the ORR catalysts for metal-air batteries has gradually received widespread attention. ${ }^{[36,98-100]}$ For example, Han et al. synthesized a type of $\mathrm{Ag} / \mathrm{C}$ ORR catalyst with large $\mathrm{Ag}$ and finer $\mathrm{Ag}$ particles, and the electrochemical performance revealed that the larger particles of $\mathrm{Ag}$ facilitated the 4-electron reduction of oxygen and the finer particles of
Ag promoted the 2-electron reduction of oxygen. ${ }^{[101]}$ On the other hand, Core-shell structured FeCo@C microspheres were successfully synthesized by $\mathrm{Xu}$ et al. via a two-step carbonization procedure with the presence of template. ${ }^{[102]} \mathrm{The}$ catalyst composed of both non-noble metal materials $\mathrm{Fe}$, Co and porous carbon shell exhibited better methanol tolerance and physical stability than those of commercial $20 \mathrm{wt} \% \mathrm{Pt} / \mathrm{C}$ catalyst. Furthermore, the performance of a $\mathrm{Zn}$-air battery with FeCo@C microspheres acting as the cathode showed higher energy density $\left(639 \mathrm{~W} \mathrm{~h} \mathrm{~kg}_{\mathrm{Zn}}{ }^{-1}\right)$, specific capacity (503 mA h $\mathrm{g}_{\mathrm{Zn}}{ }^{-1}$ ) and charge-discharge cycle stability compared to a battery equipped with the mixture of $20 \mathrm{wt} \% \mathrm{Pt} / \mathrm{C}$ and $\mathrm{RuO}_{2}$ catalysts.

\section{Heteroatom doped carbon material as ORR electrocatalyst}

Initially the carbon materials play a role of carrier in accommodating active materials and provide a reaction platform in the catalyst. In order to improve the overall ORR catalytic performance and reduce the application of scarce noble metals, nano-scale carbon materials with high specific surface areas such as graphene and carbon nanotubes were selected as support materials. ${ }^{[103,104]}$ However, reducing the cost of such high-price carbon materials is still a big challenge that cannot be underestimated.

If the carbon material can serve as the catalyst as well as the supporter, it could effectively improve the importance and performance in metal-air batteries. Extensive studies have discovered that non-metal atoms, such as $\mathrm{N}, \mathrm{S}$, P, etc. substituted $\mathrm{C}$ atoms in pristine carbon materials, can break the electrical neutrality on the surface and introduce structural defects. It has been demonstrated that high electric conductivity could be realized by heteroatoms doping in carbon materials, in which the heteroatoms such as F bonded to $\mathrm{C}$ atoms act as electron acceptors and thus promote the charge transfer of the doped carbon matrix..$^{[105,106]}$ For example, Gong et al. successfully prepared metal free N-doped CNT arrays by chemical vapor deposition method using iron (II) phthalocyanine and ammonia as precursors and studied their oxygen reduction catalytic performance. Since then, the heteroatom-doped carbon materials have been explored as the hopeful ORR catalyst for zinc-air batteries. ${ }^{[107]}$

In recent years, a variety of state-of-the-art N-doped carbon materials, such as N-doped hierarchically porous carbons, N-doped graphdiyne-like carbon and $\mathrm{N}$-doped porous carbon nanosheets, have been investigated as cathode materials for Zn-air batteries. ${ }^{[108-112]}$ For example, Liang et al. reported a kind of $\mathrm{N}$-doped carbon nanofiber aerogel prepared by pyrolysis of the bacterial cellulose and followed with an activation process in ammonia gas. ${ }^{[113]}$ As shown in Figs. 6a-c, this N-doped carbon material proved a network structure highly similar to the bacterial cellulose and satisfying ORR catalytic activity. The zinc-air battery performance using the as-prepared carbon composite material and $\mathrm{Zn}$ foil manifested the specific capacity of $615 \mathrm{mAh} \mathrm{g}^{-1}$, comparable to the battery 
using commercial $\mathrm{Pt} / \mathrm{C}$ cathode $\left(630 \mathrm{mAh} \mathrm{g}^{-1}\right)$ (Fig. 6d). It's remarkable that among the $\mathrm{N}$-doped carbon nanofiber aerogel there are three chemical forms of $\mathrm{N}$ on the $\mathrm{C}$ matrix surface, including the pyridinic $\mathrm{N}$, the pyrrolic $\mathrm{N}$ and the graphitic $\mathrm{N}$. Although it is still controversial which chemical form of $\mathrm{N}$ -
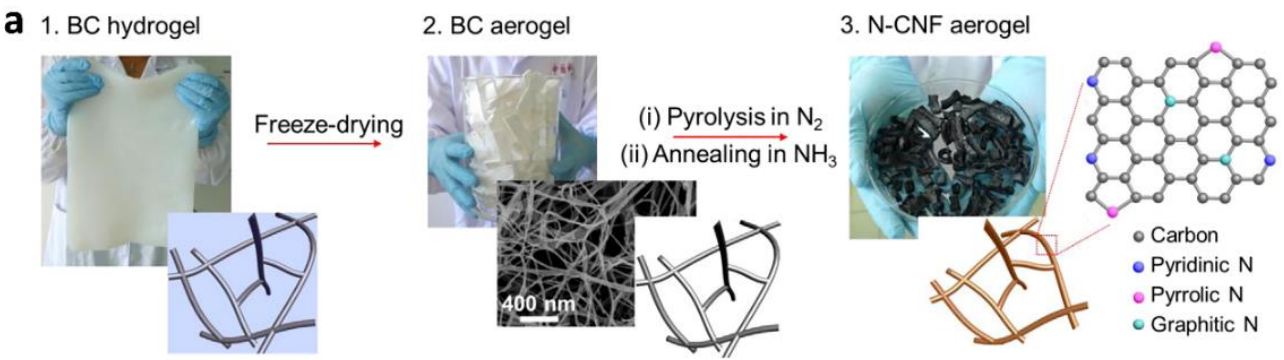

b

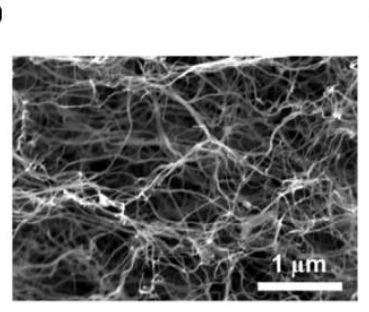

C

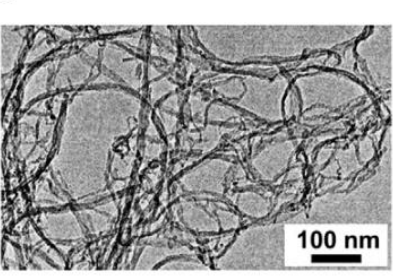

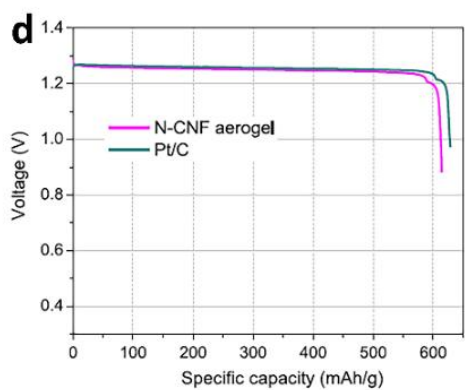

doping contributes the highest catalytic activity, there is no doubt that $\mathrm{N}$-doped $\mathrm{C}$ material displays excellent ORR performance and great potential to replace the $\mathrm{Pt} / \mathrm{C}$ electrode. ${ }^{[14-116]}$

Fig. 6 Preparation and application of the N-doped carbon nanofiber aerogel. (a) synthetic steps of the N-doped carbon nanofiber aerogel and model of fiber network, SEM (b) and TEM (c) images of the N-CNF aerogels, (d) long-term galvanostatic discharge curves of the Zn-air batteries, reproduced with the permission from [90], Copyright 2014 Elsevier Ltd.

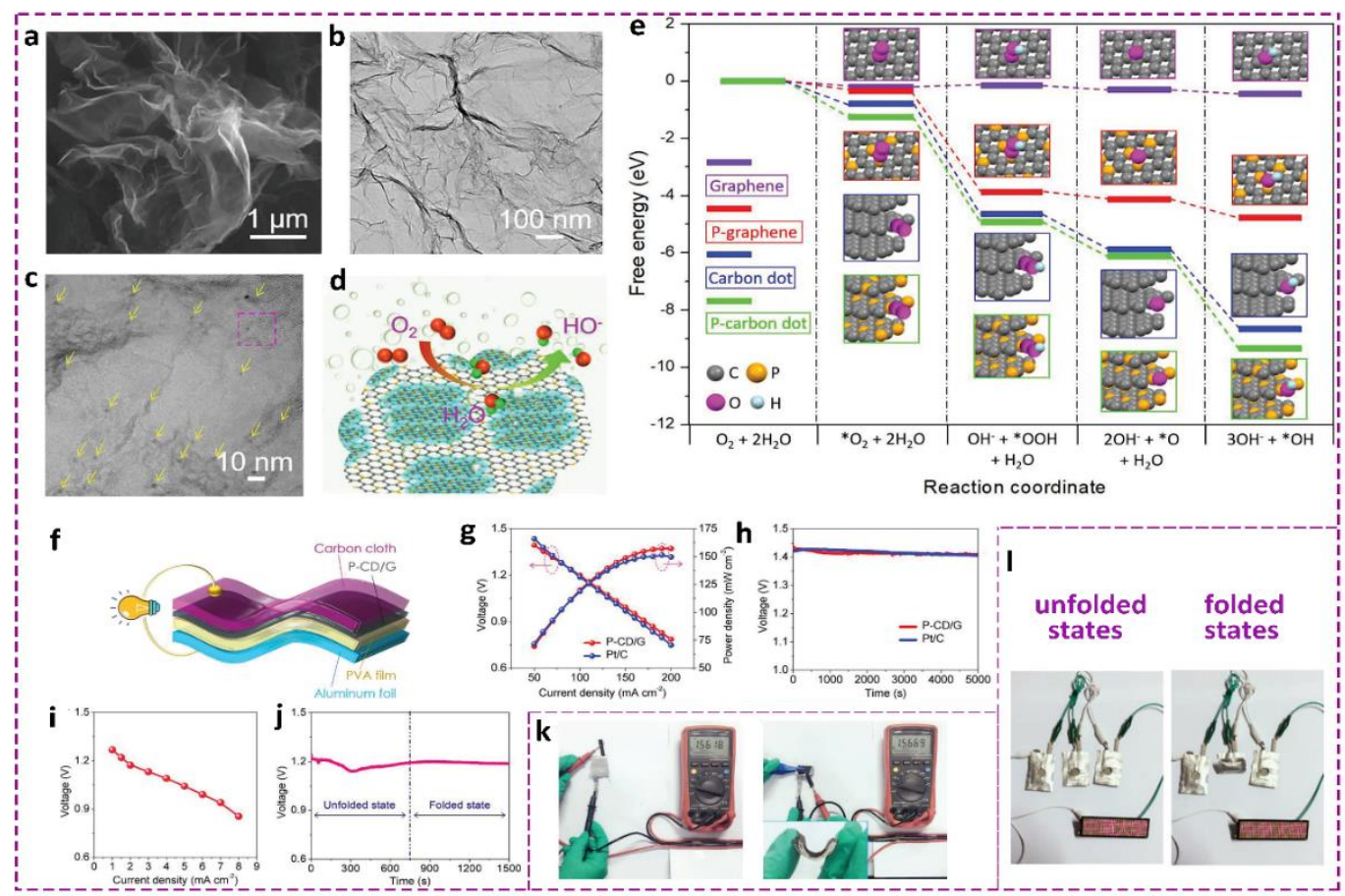

Fig. 7 Synthesis, characterization and performance test of the P-doped carbon dot/graphene (P-CD/G) nanocomposites. SEM (a) and TEM (b, c) images of the P-CD/G nanocomposites, (d) schematic illustrating the ORR on the P-CD/G nanocomposite, (e) theoretical ORR mechanism, (f) all-solid-state flexible Al-air battery model diagram, (g) plots of voltage and power density versus current density, (h) the discharge curves of the batteries, (i) plot of discharge voltages versus current density, (j) discharge curve (at different working states) of the all-solid-state Al-air battery, (k) photographs show the open circuit voltage of the solid battery working at unfolded and folded states, (l) photographs of LED screen powered by Al-air batteries working at unfolded and folded states, reproduced with the permission from [44], Copyright 2019 WILEY-VCH Verlag GmbH \& Co. KGaA, Weinheim. 
In addition to the $\mathrm{N}$ element, the doping of $\mathrm{P}$ element also theoretical model of density functional theory (DFT) are significantly promotes the ORR activity of carbon materials. shown in Figs. $7 \mathrm{~d}$ and 7e, respectively. By comparing the Wang et al. developed a biomass-deriving method combined Gibbs free energy of the intermediate species produced by with a heat treatment process to synthesize phosphorus-doped different samples in the ORR process, it can be seen that the carbon dot and successfully decorated it onto graphene matrix adsorption Gibbs free energy of the P-carbon dot to the and designated as P-doped carbon dot/graphene $(\mathrm{P}-\mathrm{CD} / \mathrm{G})$ intermediate species in each reaction step was relatively low, nanocomposites. ${ }^{[44]}$ Figs. $7 \mathrm{a}$ and $7 \mathrm{~b}$ shows the morphologies indicating effective promotion and highly preference of the and twisted structure of the sample before and after calcination, ORR reaction. More interestingly, as shown in Figs 7f-1 the Pand the yellow arrow in Fig. $7 \mathrm{c}$ indicates the carbon dots $\mathrm{CD} / \mathrm{G}$ nanocomposite catalyst delivered surprising containing $\mathrm{P}$ were successfully decorated on the graphene performance in a new-style all-solid-state flexible battery. matrix. The schematic diagram of ORR process and the

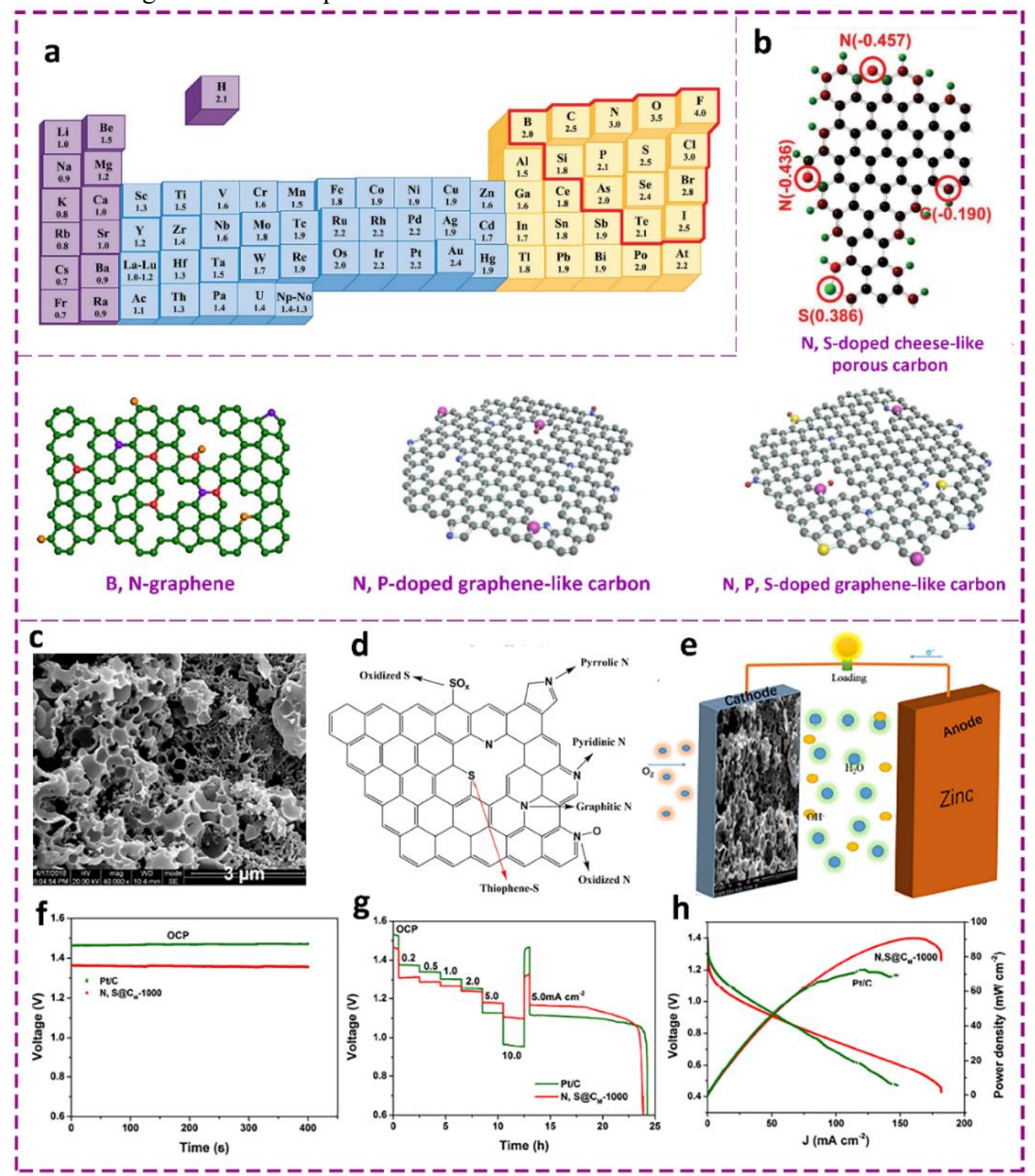

Fig. 8 (a) Periodic table and electronegativity of elements, reproduced with the permission from [44], Copyright (C) 2015 American Chemical Society; (b) schematic illustrations of ball-and-stick model for the proposed nonmetal element doped carbon material, reproduced with the permission from [57], Copyright 2018 Elsevier B.V. , reproduced with the permission from [119] and [120] Copyright WILEY-VCH Verlag GmbH \& Co. KGaA, Weinheim, (c-h) the N, S dual-doped honeycomb-like porous carbon: (c) SEM image, (d) schematic of heterocyclic $\mathrm{N}$ and $\mathrm{S}$ structures in carbon lattice, (e) schematic illustration of two electrode Zn-air battery, (f) open-circuit potential (OCP), (g) galvanostatic discharge-voltage curve, (h) polarization curves and corresponding output power density of the Zn-air battery, reproduced with the permission from [122], Copyright 2019 Elsevier Ltd. 
Generally, more than 10 kinds of elements have been demonstrated that can be doped into the carbon matrix (within the red line region of Fig. 8a). ${ }^{[17,118]}$ Several studies proved the doped carbon materials exhibited higher ORR activity than undoped samples. However, the catalytic performance of single atom doped carbon materials cannot meet the requirement of advanced $\mathrm{Zn}$-air batteries. Recently, Zheng et al. proposed double dopants with different electronegativity into the carbon matrix to further improve the electrocatalytic activity of carbonous material for ORR. They prepared $(\mathrm{B}, \mathrm{N})$ graphene by two-step doping method and observed enhanced ORR performance. ${ }^{[119]}$ Since then, double and even polyatomic doping have become a new trend to design novel catalytic materials, e.g. N/S-codoped 3D cheese-like porous carbon, $(\mathrm{N}$, $\mathrm{P})$-doped graphene, (N, P, S)-doped graphene and etc. ${ }^{[57,119-121]}$ Fig. $8 \mathrm{~b}$ depicts the skeleton diagrams of the aforementioned polyatomic doped carbon materials. Yang et al. reported a N, $\mathrm{S}$ dual-doped honeycomb-like porous carbon electrocatalyst synthesized by hard-template method, and the morphology and molecular framework model of the achieved sample are shown in Figs. $8 \mathrm{c}$ and $8 \mathrm{~d}$, respectively. ${ }^{[122]}$ A typical $\mathrm{Zn}$-air battery (Fig. 8e) was assembled with the N, S@CM-1000 as the cathode and polished $\mathrm{Zn}$ plate as the anode and the performance was shown in Figs. 8f-8h. The battery displayed an open-circuit potential (OCP) of $1.37 \mathrm{~V}$, relatively high discharge voltage at about $1.1 \mathrm{~V}$ (Compared with $\mathrm{Pt} / \mathrm{C})$ and maximum power density of $90 \mathrm{~mW} \mathrm{~cm}{ }^{-2}$. Although the discharge voltages of the N, S@CM-1000 cathode at open circuit voltage and low current density were slightly lower than those of the $\mathrm{Pt} / \mathrm{C}$ cathode, the discharge voltage at higher current density as well as power density of the N, S@CM1000 preceded the $\mathrm{Pt} / \mathrm{C}$, implying attractive prospects.

\section{Metal oxide/carbon materials as ORR electrocatalyst}

The metal oxides have received extensive attention because of low-cost, non-toxic and environmental friendliness. ${ }^{[42,123]}$ Since the metal oxides may have a variety of configurations and morphologies, their catalytic properties are significantly different. For example, $\mathrm{MnO}_{2}$ has several crystal forms and the catalytic activity order is $\alpha-\approx \delta->\gamma->\lambda->\beta-\mathrm{MnO}_{2} \cdot{ }^{[124]}$ However, the metal oxides suffer from low conductivity, low surface area and other limitations. Consequently mixing carbon material with the metal oxides can improve the electrical conductivity as well as forming $\mathrm{M}-\mathrm{O}-\mathrm{C}$ bonds in the metal oxide (MO)/C composite, which can promote the adsorption and desorption processes of the intermediate species during the catalytic reaction. ${ }^{[125,126]}$

Recent studies revealed that the metal oxide (especially the spinel-type MO) composite was suitable as ORR catalyst attributed to their attractive catalytic activity and excellent tolerance to alkaline electrolytes. Besides manganese oxides, iron, nickel and cobalt oxide are abundant in nature among the transition metal compounds, therefore the typical oxides or compounds were studied. ${ }^{[123,127,128]}$ For example, $\mathrm{Xu}$ et al. designed the $\mathrm{NiFe}_{2} \mathrm{O}_{4}$ quantum dot/CNTs $\left(\mathrm{NiFe}_{2} \mathrm{O}_{4}\right.$
(QDs)/CNTs) for both ORR and OER tests, and the results indicated the composite materials had superior conductivity as well as remarkable catalytic activity. ${ }^{[39]}$ In the composite the $\mathrm{NiFe}_{2} \mathrm{O}_{4}$ QDs adhered tightly to the surface of the CNTs and did not appear to aggregate because of the existence of the CNTs. This rational design provided plenty of catalytic sites on the surface and overcame the drawbacks of poor conductivity and low specific surface area of the intrinsic metal oxide. This catalyst exhibited high electrochemical activity, reversibility and stability in both $\mathrm{Zn}$-air primary and rechargeable battery tests. A homemade $\mathrm{Zn}$-air rechargeable battery with the $\mathrm{NiFe}_{2} \mathrm{O}_{4}$ (QDs)/CNTs catalyst showed a maximum energy density of $275 \mathrm{~mW} \mathrm{~cm}{ }^{-2}$, significantly superior to the battery with the $\mathrm{Pt} / \mathrm{C}+\mathrm{IrO}_{2}\left(84 \mathrm{~mW} \mathrm{~cm}{ }^{-2}\right)$ catalyst.

\section{Metal, metal oxide decorated heteroatom-doped carbon materials as ORR electrocatalyst}

Based on carbon materials, carbon hybrid materials integrating metals and their alloys, non-metallic atoms and metal oxides have become an important candidate for highperformance electrocatalysts. ${ }^{[129-133]}$ In recent years, the development of metal-air batteries has been greatly accelerated with the research on the high-performance ORR catalyst, especially based on the decorating metals and metal oxides accompanied with heteroatom-doped carbon materials (Fig. 9a). Figs. 9b-9d shows a variety of carbon contained catalysts in the form of metal atoms-non-metallic atomscarbon materials, metal oxides-non-metallic atoms-carbon materials, and metal oxides-non-metallic atoms-carbon materials. ${ }^{[134-136]}$ As electrode materials, these composite materials are both excellent in terms of the electrochemical catalytic properties and $\mathrm{Zn}$-air battery performance. In the codoped carbon materials, the electron-donating effect of the $\mathrm{N}$ element and the binding force of the carbon matrix can be significantly enhanced the catalytic activity of the composite materials. Simultaneously, $\mathrm{N}$ element can also increase the conductivity of the carbon materials and affect the electronic structure of the co-exist metal catalyst. Therefore, many catalysts are designed on the basis of $\mathrm{N}$-doped carbon materials. ${ }^{[137,138]}$ For example, Kim et al. synthesized $\mathrm{N}$ doped graphene material with two-dimensional (2D) $\mathrm{Co}_{3} \mathrm{O}_{4}$ nano polyhedron $\left(\mathrm{Co}_{3} \mathrm{O}_{4}\right.$ grown on $\mathrm{Fe}$, abbreviated the sample as $\left.\mathrm{NP} \mathrm{Co}_{3} \mathrm{O}_{4} / \mathrm{Fe} @ \mathrm{C}_{2} \mathrm{~N}\right)$ and the samples showed comparable Tafel slopes for both ORR and OER to that of commercial Pt/C and $\mathrm{IrO}_{2}$ catalysts respectively. ${ }^{[139]}$ Furthermore, the improved electrochemical performance of $\mathrm{NP} \mathrm{Co}_{3} \mathrm{O}_{4} / \mathrm{Fe} @ \mathrm{C}_{2} \mathrm{~N}$ contrast to that of $\mathrm{NP} \mathrm{C}_{3} \mathrm{O}_{4}$ or $\mathrm{Fe} @ \mathrm{C}_{2} \mathrm{~N}$ catalyst demonstrated the former was an prominent catalyst for metal-air batteries. In addition, the results also suggested the interaction between NP $\mathrm{Co}_{3} \mathrm{O}_{4}$ and $\mathrm{Fe} @ \mathrm{C}_{2} \mathrm{~N}$ was a key factor for catalytic activity enhancement.

Although the recent reported carbon-based composite catalysts show remarkable ORR performance, the sophisticated preparation process of the materials is not 
suitable for large-scale production. ${ }^{[140-142]}$ How to simplify the synthetic process of the functional carbon materials and multicomponent catalysts drives the researchers to optimize the synthetic strategy. Carbonization of the organic compounds in inert atmosphere is the most common method for the preparation of the carbonaceous components, and introducing the metal ions or metal oxides into the organic compounds and following calcination is another traditional approach to preparing complex component catalysts. ${ }^{[143,144]}$ By incorporating the iron and copper ions into the ZIF-8 salts, Wang and co-workers successfully synthesized the $\mathrm{Cu} @ \mathrm{Fe}-\mathrm{N}$ $\mathrm{C}$ composite material with high specific surface area, bimetallic activity site and high nitrogen doping level, which also revealed high durability in acidic and alkaline electrolyte as well as inhibited methanol induced corrosion. ${ }^{[145]}$
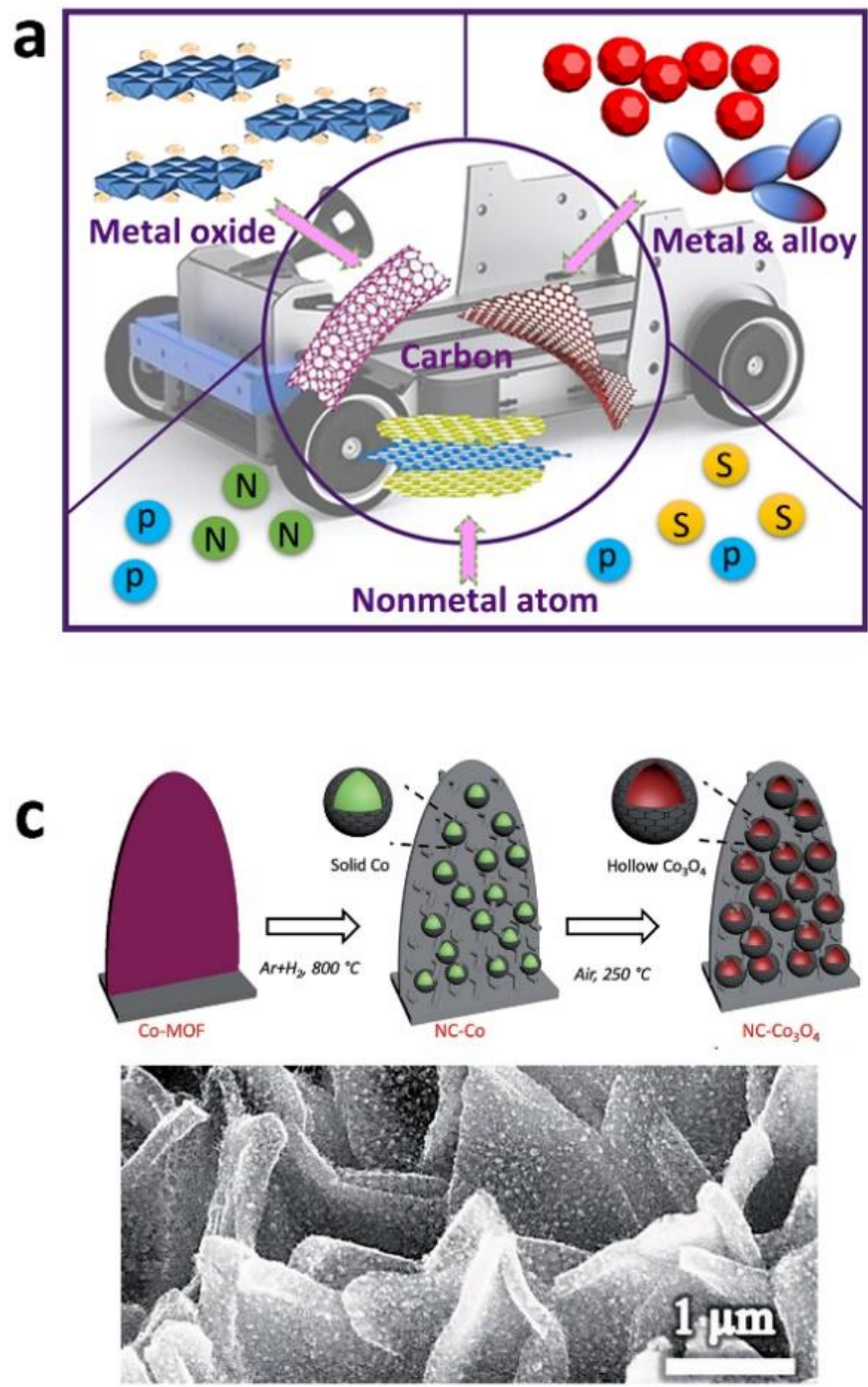

$\mathrm{N}$-Carbon- $\mathrm{CO}_{3} \mathrm{O}_{4}$ arrays
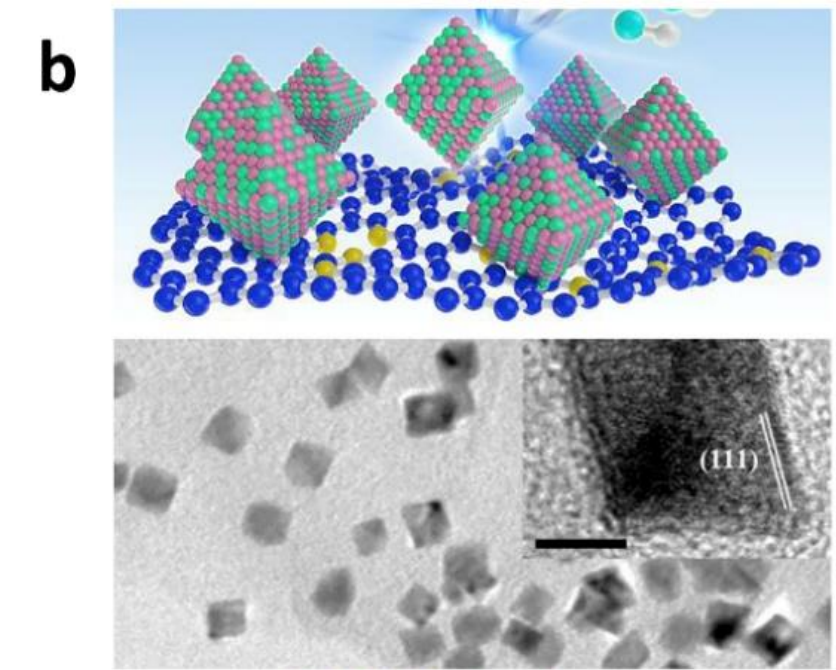

PtNi-N-Carbon

Electrochemical test showed the performance of the $\mathrm{Cu} @ \mathrm{Fe}$ $\mathrm{N}-\mathrm{C}$ was comparable to the Pt catalyst in acidic electrolyte as well as superior to $\mathrm{Pt}$ in alkaline electrolyte. The $\mathrm{Zn}$-air battery assembled with the $\mathrm{Cu} @ \mathrm{Fe}-\mathrm{N}-\mathrm{C}$ electrode had a peak power density of $92 \mathrm{~mW} \mathrm{~cm}^{-2}$, which was better than that of the $\mathrm{Pt} / \mathrm{C}$ electrode $\left(74 \mathrm{~mW} \mathrm{~cm}^{-2}\right)$. The galvanostatic discharge results revealed only a small activity loss after 50000-second constant current discharge at a current density of $20 \mathrm{~mA} \mathrm{~cm}^{-2}$, implying excellent stability. An increasing number of reports verified that various organic compounds, such as $\mathrm{Ni}$ incorporated polyamine, polystyrene spheres and $\mathrm{N}, \mathrm{N}$-dimethylformamide etc., could be utilized to synthesize novel electrocatalysts with outstanding ORR activity comparable to that of noble metalbased catalysts. ${ }^{[45,146-148]}$
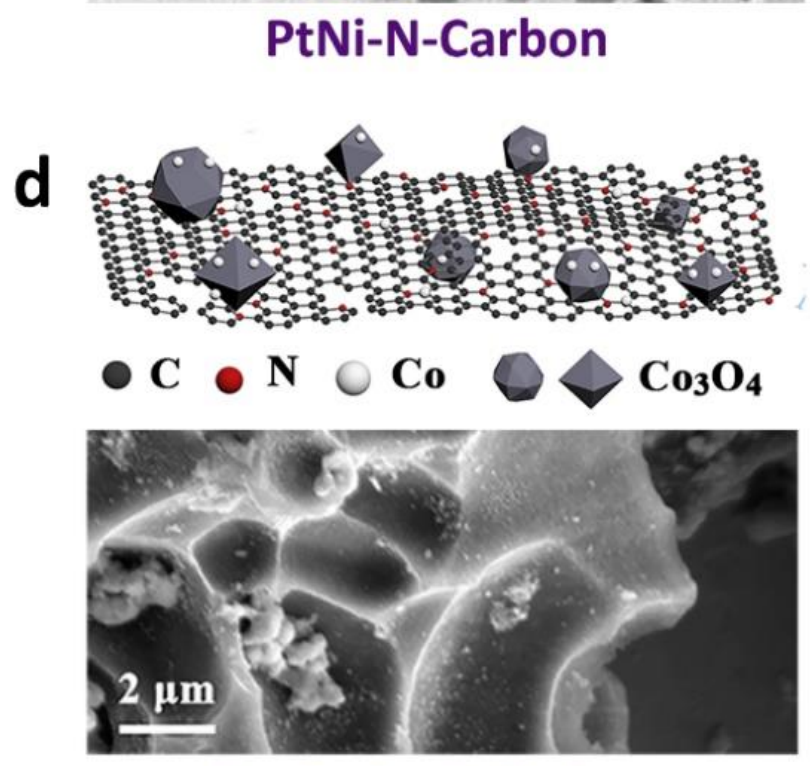

$\mathrm{Co}-\mathrm{CO}_{3} \mathrm{O}_{4}-\mathrm{N}-\mathrm{Carbon}$

Fig. 9 (a) Composition of compound catalysts, (b) schematic diagram and TEM picture of the PtNi-NC material, reproduced with the permission from [134], Copyright 2020 Elsevier B.V., (c) schematic diagram and SEM picture of the $\mathrm{Co}_{3} \mathrm{O}_{4}-\mathrm{NC}_{\text {material, }}$ reproduced with the permission from [135], Copyright 2017 WILEY-VCH Verlag GmbH \& Co. KGaA, Weinheim, (d) Schematic diagram and SEM picture of the $\mathrm{Co}-\mathrm{Co}_{3} \mathrm{O}_{4}-\mathrm{NC}$ material, reproduced with the permission from [136], Copyright (C) 2019 Elsevier B.V. 
With the increasing applications of biomass-derived carbon materials in energy storage fields, the employment of biomaterials to synthesize hybrid carbon-based electrocatalysts has gradually become a hotspot. Discarded biomass resources can be utilized to prepare a wide variety of carbon materials, such as carbon fiber, activated carbon, graphene, etc. ${ }^{[149-151]}$ However, the synthetic processes usually combine with treatments such as pyrolysis, chemical vapor deposition (CVD) and circulating oxidation, as well as participation of the graphitic catalysts. ${ }^{[152-154]}$ The biomassderived carbon materials provides novel suggestions for designing high-performance catalyst for metal-air battery, developing green synthetic process and reducing resource wastage. ${ }^{[155,156]}$

More importantly, most biomass precursor contains a large amount of trace elements, such as N, S and P, etc., which can exist in the form of doped heteroatoms among the achieved materials. ${ }^{[157,158]}$ Some natural biological materials contain a variety of organic components as carbon frameworks precursors and metal and nonmetal elements, making them ideal for preparing co-doped carbon composites material with catalytic activities. As shown in Fig. 10a, Wu et al. synthesized $\mathrm{N}, \mathrm{P}$, and $\mathrm{Fe} /$ carbon mesoporous microspheres (egg-CMS) by mixing eggs and ethyl orthosilicate, and followed by a series of physicochemical treatments. ${ }^{[159]}$ The SEM images (Figs. $10 \mathrm{~b}, 10 \mathrm{c})$ of the samples displayed similar microsphere
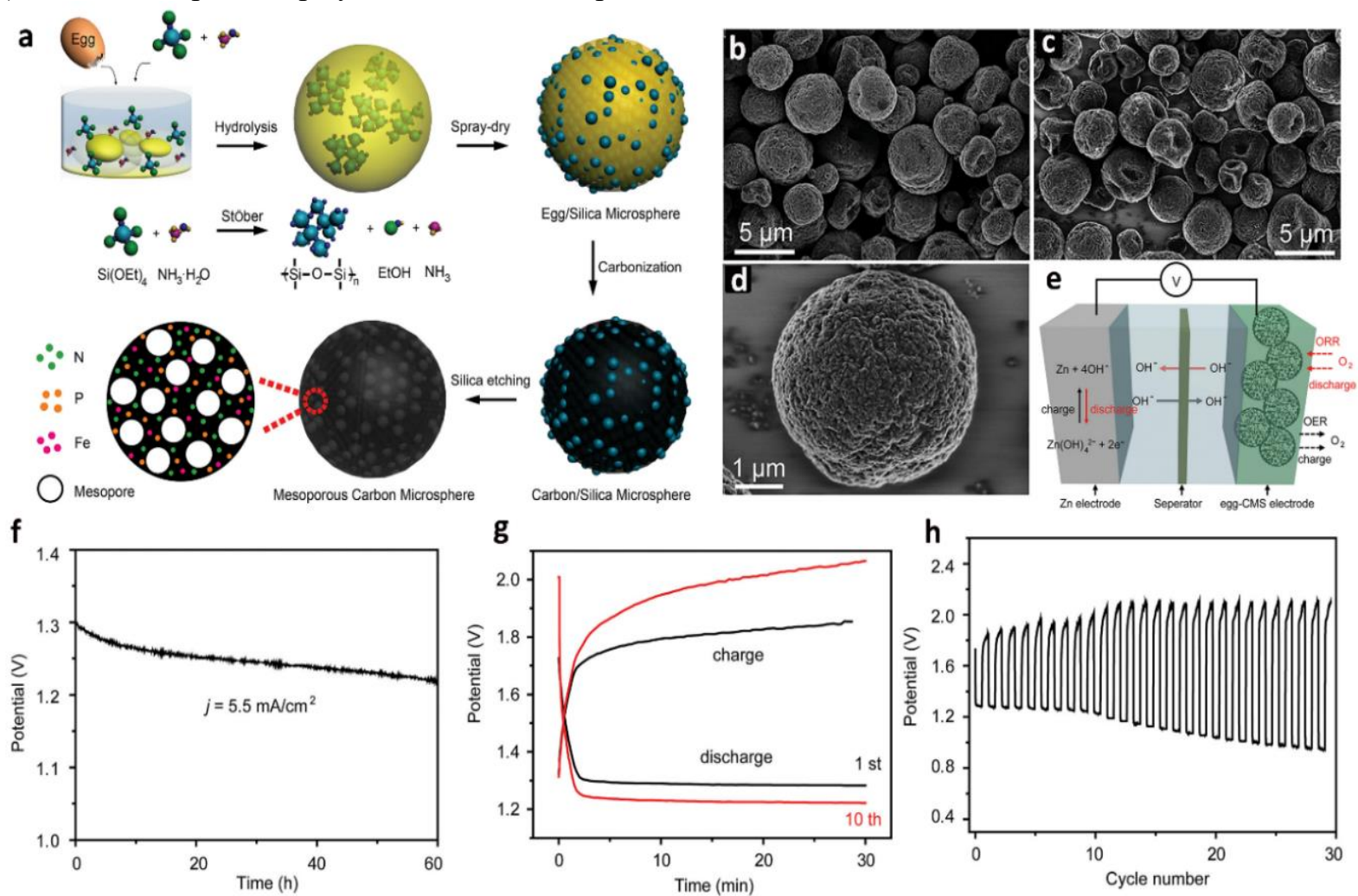

Fig. 10 Carbon based materials were synthesized with eggs and ethyl orthosilicate. (a) Schematic illustration of the fabrication of the N, P, and Fe co-doped mesoporous carbon microspheres (egg-CMS). (b, c) SEM images of the egg-CMS with and without silica, (d) high resolution SEM image of the egg-CMS, (e) schematic of two-electrode Zn-air battery, (f) discharge curve of Zn-air battery with egg-CMS as ORR electrocatalyst, (g) charge and discharge curves and (h) cycling performance of rechargeable Zn-air battery, reproduced with the permission from [159], Copyright 2016 WILEY-VCH Verlag GmbH \& Co. KGaA, Weinheim. 
Table 1. Electrochemical performance for carbon-based composite catalysts as cathode materials in tested ZAbs.

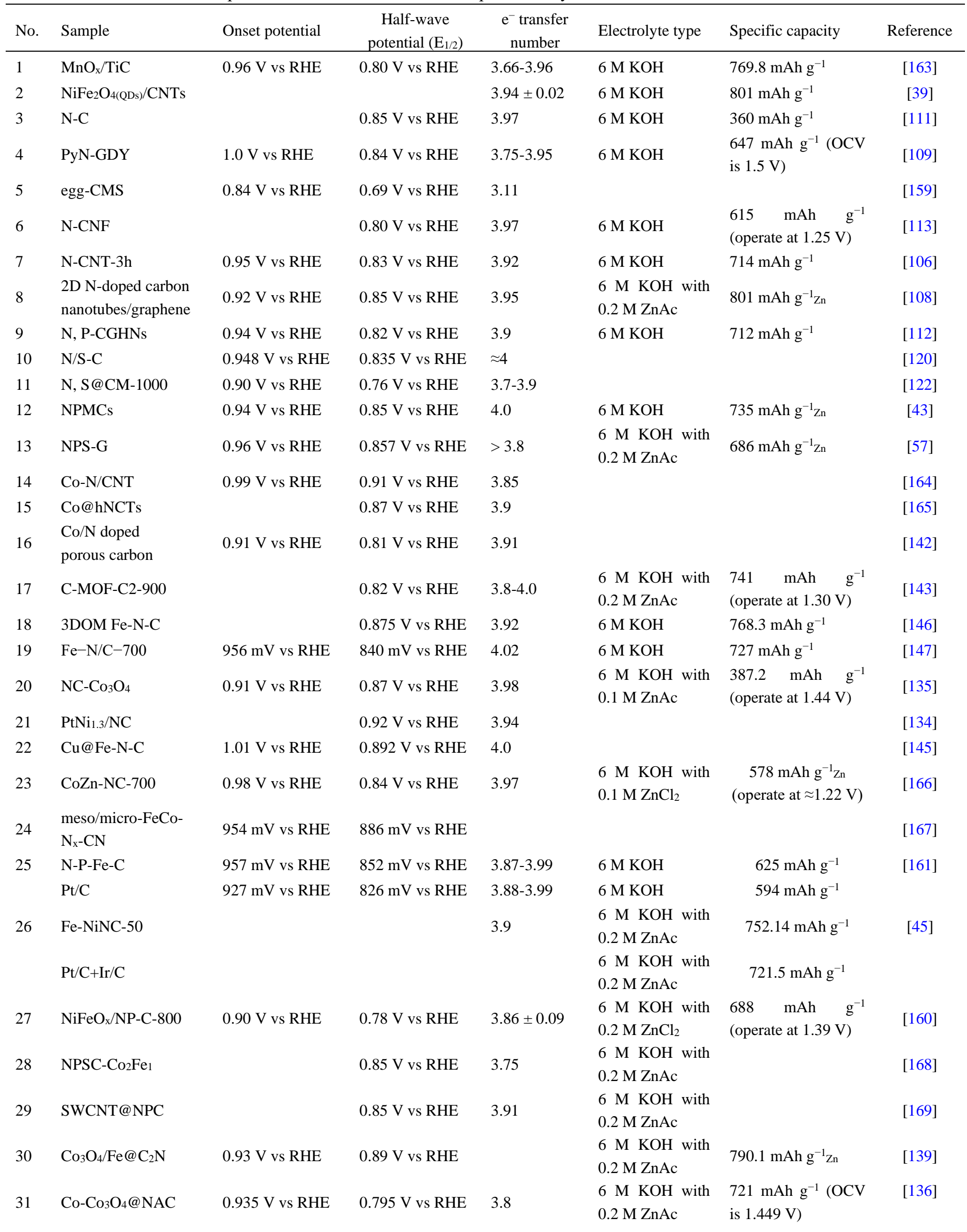




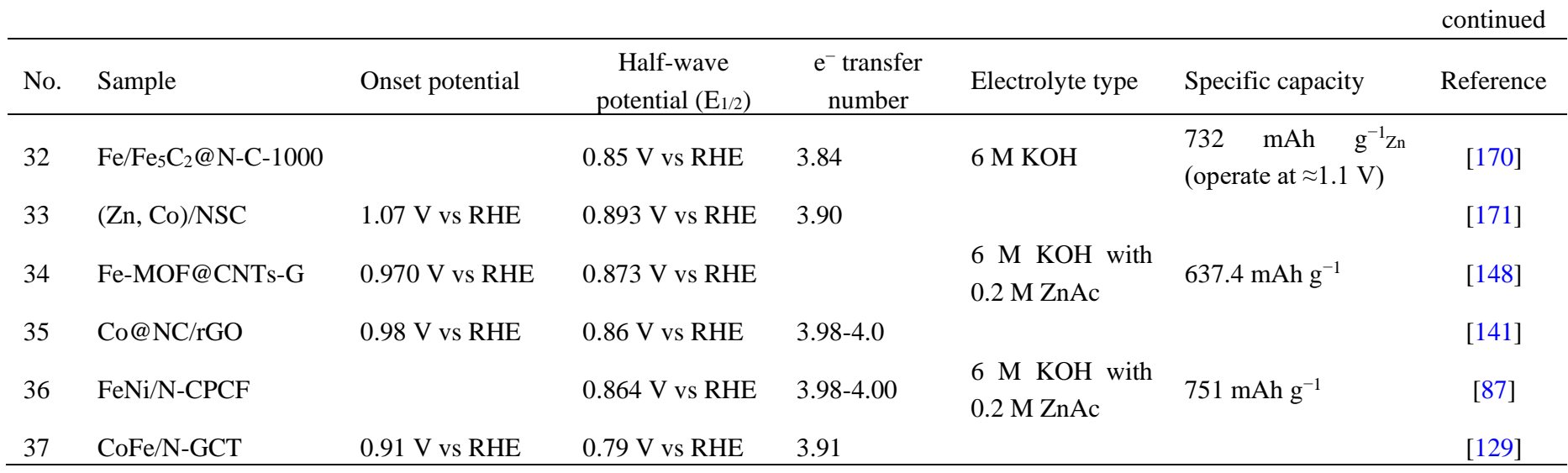

The waste biomass resources existed in all countries and regions. It is believed that sufficient biomass resources can be recycled and utilized to promote the novel ORR catalyst and further extend to the Zn-air battery. ${ }^{[161]}$ The composition, electron transfer number and properties of selected carbonbased catalysts are shown in Table 1. Most of the carbon-based catalysts exhibit comparable electrochemical performance to the noble metal-based catalysts.

\section{Summary, challenges and perspectives}

$\mathrm{Zn}$-air batteries will undoubtedly attract the interests of researchers for a long time in the future because they meet the urgent requirements of social development on energy with prominent advantages of environmental friendliness and desirable energy density. Moreover, the development of carbon-based catalysts with low cost and high efficiency is a crucial factor in the popularization of this kind of energy storage device. In this paper, the research progress of carbon composites as ORR catalyst and their performance evaluated by the metal-air batteries in recent years have been reviewed. The structure improvement, composition optimization, synthesis strategy and functionalization of carbon-based catalyst have been systematically analyzed. The developments of the carbon-based catalysts show following characteristics:

(i) Initially, the researches of carbon materials mainly focused on the graphene and CNTs. Moreover, the structure of carbon materials was relatively simple and mostly sheet or tube-like. With the selection of carbon sources and the gradual diversification of synthesis routes, the structure of carbon materials exhibits difference morphologies, such as bamboo shape, spherical shape, bowl shape, etc., and hierarchical hybrid structure.

(ii) Various species can replace noble metal Pt. In other words, metal atoms, alloys, non-metal atoms and transition metal oxides can combine with carbon materials to form catalysts with excellent catalytic performance. ${ }^{[162]} \mathrm{Pt} / \mathrm{C}$ has been transformed from the leading role of research to a standard for performance comparison. Gradually, metal-free carbon-based catalysts and co-doped carbon-based catalysts have become the hotspots.

(iii) The function of carbon materials in the composite catalyst has changed obviously. In addition to the supporting function, it also reveals the synergistic effect to promote the catalytic performance of the ORR. The carbon materials doped with nonmetal heteroatoms are promising to provide excess catalytic activity.

(iv) Carbon-based composite catalysts show excellent electrocatalytic performance. In addition, the $\mathrm{Zn}$-air battery with this kind of cathode shows comparable specific capacity, cyclical stability, and corrosion resistance corresponds to noble metal-based catalyst cathode.

Although great breakthroughs in the research of carbonbased catalysts have been made in recent years, there are still some obstacles to achieve the goal of real application or largescale production, and the main challenges are as follows:

(i) At present, there is no unified conclusion for the location of catalytic active center in carbon materials doped with heteroatom elements, and the fundamentals of improving the catalytic performance still need further explorations.

(ii) Rechargeable battery is considered as one of the main research topics. The design of bifunctional carbon-based catalyst with high activity, high stability and high compatibility for rechargeable $\mathrm{Zn}$-air batteries need to be further developed.

(iii) So far, most of the successful projects of carbon-based catalytic materials have been completed in the laboratory, relevant studies are urgently required to improve the technical maturity for real application or large-scale production in factory.

(iv) It is also important to pay attention to the economical and environmentally friendly biomass-derived carbon materials. In addition, there is no efficient method until now to control the contents of doped or decorated elements in biomass carbon materials.

Although significant progress has been made in the development of novel ORR catalysts such as metal/carbon, nonmetal atom/carbon, metal oxide/carbon and metal-metal oxide-nonmetal atom carbon materials in recent years, it is still necessary to optimize the synthetic process and introduce more suitable raw materials as well as further understanding the mechanism of performance improvement. Doubtlessly, reasonable structure design, elements and component 
optimization and synthetic process simplification will overcome the shortage of state-of-the-art carbon-based ORR catalysts and apply to the Zn-air battery as well as other energy storage devices.

\section{Acknowledgement}

This work was supported by National Natural Science Foundation of China (No. 21805304 and 51572031) and Civil Aerospace Technology Research Project (B0108) Extraterrestrial In-situ water Extraction and photochemical synthesis of hydrogen and oxygen.

\section{Supporting information}

Not applicable

\section{Conflict of interest}

There are no conflicts to declare.

\section{References}

[1] J. Lu, T. Wu, K. Amine, Nature Energy, 2017, 2, 17011, doi: 10.1038/nenergy.2017.11.

[2] S. Chu, Y. Cui, N. Liu, Nat. Mater., 2017, 16, 16-22, doi: 10.1038/nmat4834

[3] W. Wang, J. Zhou, Z. Wang, L. Zhao, P. Li, Y. Yang, C. Yang, H. Huang, S. Guo, Adv. Energy Mater., 2018, 8, 1701648, doi: 10.1002/aenm.201701648.

[4] H. Lei, X. Li, J. Meng, H. Zheng, W. Zhang, R. Cao, ACS Catal., 2019, 9, 4320-4344, doi: 10.1021/acscatal.9b00310.

[5] L. Chong, J. Wen, J. Kubal, F. G. Sen, J. Zou, J. Greeley, M. Chan, H. Barkholtz, W. Ding, D.-J. Liu, Science, 2018, 362, 1276-1281, doi: 10.1126/science.aau0630.

[6] S. Ni, J. Liu, D. Chao, L. Mai, Adv. Energy Mater., 2019, 9 , 1803324, doi: 10.1002/aenm.201803324.

[7] F. Wang, O. Borodin, T. Gao, X. Fan, W. Sun, F. Han, A. Faraone, J. A. Dura, K. Xu, C. Wang, Nat. Mater., 2018, 17, $543-$ 549, doi: 10.1038/s41563-018-0063-z.

[8] H. J. Kwon, J. Y. Hwang, H. J. Shin, M. G. Jeong, K. Y. Chung, Y. K. Sun, H. G. Jung, Nano lett., 2020, 20, 625-635, doi: 10.1021/acs.nanolett.9b04395.

[9] Y. Li, J. Lu, ACS Energy Lett., 2017, 2, 1370-1377,doi: 10.1021/acsenergylett.7b00119.

[10] V. M. Dhavale, S. Kurungot, ACS Catal., 2015, 5, $1445-$ 1452, doi: 10.1021/cs501571e.

[11] Y. S. Wei, M. Zhang, M. Kitta, Z. Liu, S. Horike, Q. Xu, J. Am. Chem. Soc, 2019, 141, 7906-7916, doi: 10.1021/jacs.9b02417.

[12] X. Tian, X. F. Lu, B. Y. Xia, X. W. Lou, Joule, 2020, 4, 45 68, doi: 10.1016/j.joule.2019.12.014.

[13] F. Li, Y. Yin, C. Zhang, W. Li, K. Maliutina, Q. Zhang, Q. Wu, C. He, Y. Zhang, M. Yang, L. Fan, Appl. Catal. B: Environ., 2020, 263, 118297, doi: 10.1016/j.apcatb.2019.118297.

[14] L. maiche, French patent, 1878, 127069.

[15] H.-F. Wang, Q. Xu, Matter, 2019, 1, 565-595, doi: 10.1016/j.matt.2019.05.008.

[16] J. Liu, H. Liu, H. Chen, X. Du, B. Zhang, Z. Hong, S. Sun, W. Wang, $A d v$. Sci.,2020, 7, 1901614, doi: 10.1002/advs.201901614.

[17] C. Wei, R. R. Rao, J. Peng, B. Huang, I. E. L. Stephens, M. Risch, Z. J. Xu, Y. Shao-Horn, Adv. Mater.,2019, 31, 1806296, doi: 10.1002/adma.201806296.

[18] S. Liu, Y. Yin, Y. Shen, K. S. Hui, Y. T. Chun, J. M. Kim, K. N. Hui, L. Zhang, S. C. Jun, Small, 2020, 16, 1906458, doi: 10.1002/smll.201906458.

[19] X. Ge, A. Sumboja, D. Wuu, T. An, B. Li, F. W. T. Goh, T. S. A. Hor, Y. Zong, Z. Liu, ACS Catal., 2015, 5, 4643-4667, doi: 10.1021/acscatal.5b00524.

[20] H. W. Kim, V. J. Bukas, H. Park, S. Park, K. M. Diederichsen, J. Lim, Y. H. Cho, J. Kim, W. Kim, T. H. Han, J. Voss, A. C. Luntz, B. D. McCloskey, ACS Catal., 2019, 10, 852863, doi: 10.1021/acscatal.9b04106.

[21] Y. Lian, W. Yang, C. Zhang, H. Sun, Z. Deng, W. Xu, L. Song, Z. Ouyang, Z. Wang, J. Guo, Y. Peng, Angew. Chem. Int. Ed., 2020, 59, 286-294, doi: 10.1002/anie.201910879.

[22] Q. Yang, Y. Jia, F. Wei, L. Zhuang, D. Yang, J. Liu, X. Wang, S. Lin, P. Yuan, X. Yao, Angew. Chem. Int. Ed., 2020, doi: 10.1002/anie.202000324.

[23] Z. Ma, S. Li, L. Wu, L. Song, G. Jiang, Z. Liang, D. Su, Y. Zhu, R. R. Adzic, J. X. Wang, Z. Chen, Nano Energy, 2020, 69, 104455, doi: 10.1016/j.nanoen.2020.104455.

[24] J. H. Kim, J. Y. Cheon, T. J. Shin, J. Y. Park, S. H. Joo, Carbon, 2016, 101, 449-457, doi: 10.1016/j.carbon.2016.02.014.

[25] J. W. Hong, S. U. Lee, Y. W. Lee, S. W. Han, J. Am. Chem. Soc., 2012, 134, 4565-4568, doi: 10.1021/ja300598u.

[26] M. Shao, Q. Chang, J.-P. Dodelet, R. Chenitz, Chem. Rev., 2016, 116, 3594-3657, doi: 10.1021/acs.chemrev.5b00462.

[27] S. Li, X. Tang, H. Jia, H. Li, G. Xie, X. Liu, X. Lin, H.-J. Qiu, J. Catal., 2020, 383, 164-171, doi: 10.1016/j.jcat.2020.01.024.

[28] R. Ge, L. Li, J. Su, Y. Lin, Z. Tian, L. Chen, Adv. Energy Mater., 2019, 9, 1901313, doi: 10.1002/aenm.201901313.

[29] Z. Li, W. Niu, Z. Yang, N. Zaman, W. Samarakoon, M. Wang, A. Kara, M. Lucero, M. V. Vyas, H. Cao, H. Zhou, G. E. Sterbinsky, Z. Feng, Y. Du, Y. Yang, Energy Environ. Sci., 2020, doi: 10.1039/c9ee02657f.

[30] Y.-J. Wang, H. Fan, A. Ignaszak, L. Zhang, S. Shao, D. P. Wilkinson, J. Zhang, Chem. Eng. J., 2018, 348, 416-437, doi: 10.1016/j.cej.2018.04.208.

[31] H. W. Liang, W. Wei, Z. S. Wu, X. Feng, K. Mullen, J. Am. Chem. Soc.,2013, 135, 16002-16005, doi: 10.1021/ja407552k.

[32] H. F. Wang, L. Chen, H. Pang, S. Kaskel, Q. Xu, Chem. Soc. Rev., 2020, doi: 10.1039/c9cs00906j.

[33] H. Khani, N. S. Grundish, D. O. Wipf, J. B. Goodenough, $A d v$. Energy Mater., 2019, 10, 1903215, doi: 10.1002/aenm.201903215.

[34] C. Tang, Q. Zhang, Adv. Mater, 2017, 29, doi: 10.1002/adma.201604103.

[35] L. Tao, Y. Wang, Y. Zou, N. Zhang, Y. Zhang, Y. Wu, Y. Wang, R. Chen, S. Wang, Adv. Energy Mater., 2019, 1901227, doi: 10.1002/aenm.201901227.

[36] D. Wang, D. Astruc, Chem. Soc. Rev., 2017, 46, 816-854, 
doi: 10.1039/c6cs00629a.

[37] J. Liu, M. Jiao, L. Lu, H. M. Barkholtz, Y. Li, Y. Wang, L. Jiang, Z. Wu, D. J. Liu, L. Zhuang, C. Ma, J. Zeng, B. Zhang, D. Su, P. Song, W. Xing, W. Xu, Y. Wang, Z. Jiang, G. Sun, Nat. Commun., 2017, 8, 15938, doi: 10.1038/ncomms15938.

[38] C. Mu, J. Mao, J. Guo, Q. Guo, Z. Li, W. Qin, Z. Hu, K. Davey, T. Ling, S. Z. Qiao, Adv. Mater., 2020, 1907168, doi: 10.1002/adma.201907168.

[39] N. Xu, Y. Zhang, T. Zhang, Y. Liu, J. Qiao, Nano Energy, 2019, 57, 176-185, doi: 10.1016/j.nanoen.2018.12.017.

[40] Z. Zhou, S. Wang, W. Zhou, G. Wang, L. Jiang, W. Li, S. Song, J. Liu, G. Sun, Q. Xin, Chem. Commun., 2003, 394-5, doi: 10.1039/b211075j.

[41] W. Qian, R. Hao, J. Zhou, M. Eastman, B. A. Manhat, Q. Sun, A. M. Goforth, J. Jiao, Carbon, 2013, 52, 595-604, doi: 10.1016/j.carbon.2012.10.031.

[42] H. Zhang, H. Qiao, H. Wang, N. Zhou, J. Chen, Y. Tang, J. Li, C. Huang, Nanoscale, 2014, 6, 10235-10242, doi: $10.1039 / \mathrm{c} 4 \mathrm{nr} 02125 \mathrm{~h}$.

[43] J. Zhang, Z. Zhao, Z. Xia, L. Dai, Nat. Nanotechnol., 2015, 10, 444-452, doi: 10.1038/nnano.2015.48.

[44] M. Wang, Y. Li, J. Fang, C. J. Villa, Y. Xu, S. Hao, J. Li, Y. Liu, C. Wolverton, X. Chen, V. P. Dravid, Y. Lai, Adv. Energy Mater., 2019, 10, 1902736, doi: 10.1002/aenm.201902736.

[45] X. Zhu, D. Zhang, C.-J. Chen, Q. Zhang, R.-S. Liu, Z. Xia, L. Dai, R. Amal, X. Lu, Nano Energy, 2020, 71, 104597 ,doi: 10.1016/j.nanoen.2020.104597.

[46] L. Dubau, T. Asset, R. Chattot, C. Bonnaud, V. Vanpeene, J. Nelayah, F. Maillard, ACS Catal.,2015, 5, 5333-5341,doi: 10.1021/acscatal.5b01248.

[47] N. Ranjbar Sahraie, J. P. Paraknowitsch, C. Gobel, A. Thomas, P. Strasser, J. Am. Chem. Soc., 2014, 136, 14486-14497, doi: 10.1021/ja506553r.

[48] M. Jiang, C. Fu, R. Cheng, W. Zhang, T. Liu, R. Wang, J. Zhang, B. Sun, Adv. Sci., 2020, 7, 2000747, doi: 10.1002/advs.202000747.

[49] G. Guan, M. Y. Han, $A d v$. Sci., 2019, 6, 1901837, doi: 10.1002/advs.201901837.

[50] Y. Huang, Y. Wang, C. Tang, J. Wang, Q. Zhang, Y. Wang, J. Zhang, Adv. Mater., 2019, 31, e1803800, doi: 10.1002/adma.201803800.

[51] T. Liu, L. Zhang, B. Cheng, J. Yu, Adv. Energy Mater., 2019, 9, 1803900, doi: 10.1002/aenm.201803900.

[52] W.-J. Niu, Y.-P. Wang, J.-Z. He, W.-W. Liu, M.-C. Liu, D. Shan, L. Lee, Y.-L. Chueh, Nano Energy, 2019, 63, 103788, doi: 10.1016/j.nanoen.2019.05.074.

[53] H.-M. Zhang, Y. Zhao, Y. Zhang, M. Zhang, M. Cheng, J. Yu, H. Liu, M. Ji, C. Zhu, J. Xu, Chem. Eng. J., 2019, 375, 122058 , doi: 10.1016/j.cej.2019.122058.

[54] D. Guo, H. Wei, X. Chen, M. Liu, F. Ding, Z. Yang, Y. Yang, S. Wang, K. Yang, S. Huang, J. Mater. Chem. A, 2017, 5, $18193-$ 18206, doi: 10.1039/c7ta04728b.

[55] Y. Cheng, Y. Guo, N. Zhang, S. Tao, Z. Liao, Y. Wang, Z. Xiang, Nano Energy, 2019, 63, 103897, doi: 10.1016/j.nanoen.2019.103897.
[56] S. Chen, L. Zhao, J. Ma, Y. Wang, L. Dai, J. Zhang, Nano Energy, 2019, 60, 536-544, doi: 10.1016/j.nanoen.2019.03.084. [57] X. Zheng, J. Wu, X. Cao, J. Abbott, C. Jin, H. Wang, P. Strasser, R. Yang, X. Chen, G. Wu, Appl. Catal. B: Environ., 2019 241, 442-451, doi: 10.1016/j.apcatb.2018.09.054.

[58] Z. Pei, Z. Yuan, C. Wang, S. Zhao, J. Fei, L. Wei, J. Chen, C. Wang, R. Qi, Z. Liu, Y. Chen, Angew. Chem. Int. Ed., 2020, 59, 4793-4799, doi: 10.1002/anie.201915836.

[59] L. Jiang, J. Duan, J. Zhu, S. Chen, M. Antonietti, ACS nano, 2020, 14, 2436-2444, doi: 10.1021/acsnano.9b09912.

[60] Y. Zhao, Q. Lai, Y. Wang, J. Zhu, Y. Liang, ACS Appl. Mater. Inter, 2017, 9, 16178-16186, doi: 10.1021/acsami.7b01712.

[61] X. Li, X. Gao, P. Xu, C. You, W. Sun, X. Wang, Q. Lin, S. Liao, ACS Sustain. Chem. Eng., 2019, 7, 7148-7154, doi: 10.1021/acssuschemeng.9b00126.

[62] Y. Qin, H.-H. Wu, L. A. Zhang, X. Zhou, Y. Bu, W. Zhang, F. Chu, Y. Li, Y. Kong, Q. Zhang, D. Ding, Y. Tao, Y. Li, M. Liu, X. C. Zeng, ACS Catal., 2018, 9, 610-619, doi: 10.1021/acscatal.8b04117.

[63] X. Wu, Y. Niu, B. Feng, Y. Yu, X. Huang, C. Zhong, W. Hu, C. M. Li, ACS Appl. Mater. Inter., 2018, 10, 20440-20447, doi: 10.1021/acsami.8b04012.

[64] X. Wang, Y. Li, T. Jin, J. Meng, L. Jiao, M. Zhu, J. Chen, NanoLett., 2017, 17, 7989-7994, doi: 10.1021/acs.nanolett.7b04502.

[65] Y. Dou, W. Zhang, A. Kaiser, Adv. Sci., 2020, 7, 1902590,doi: 10.1002/advs.201902590.

[66] T. Cai, Y. Huang, M. Huang, Y. Xia, D. Pang, W. Zhang, Chem. Eng. J., 2019, 371, 544-553,doi: 10.1016/j.cej.2019.04.025.

[67] P. Liu, Y. Hu, X. Liu, T. Wang, P. Xi, S. Xi, D. Gao, J. Wang, J. Mater. Chem. A, 2019, 7, 12851-12858, doi: 10.1039/C9TA02894C.

[68] L. Qin, W. Lv, W. Wei, F. Kang, D. Zhai, Q.-H. Yang, Carbon, 2019, 141, 561-567, doi: 10.1016/j.carbon.2018.10.025. [69] H. Sun, M. Wang, X. Du, Y. Jiao, S. Liu, T. Qian, Y. Yan, C. Liu, M. Liao, Q. Zhang, L. Meng, L. Gu, J. Xiong, C. Yan, J. Mater. Chem. A, 2019, 7, 20952-20957, doi: 10.1039/C9TA06949F.

[70] H. Jiang, J. Gu, X. Zheng, M. Liu, X. Qiu, L. Wang, W. Li, Z. Chen, X. Ji, J. Li, Energy Environ. Sci., 2019, 12, 322-333, doi: 10.1039/c8ee03276a.

[71] J. Niu, R. Shao, M. Liu, Y. Zan, M. Dou, J. Liu, Z. Zhang, Y. Huang, F. Wang, Adv. Funct. Mater., 2019, 29, 1905095, doi: 10.1002/adfm.201905095.

[72] S. Chen, Y. Zheng, B. Zhang, Y. Feng, J. Zhu, J. Xu, C. Zhang, W. Feng, T. Liu, ACS Appl. Mater. Interface, 2019, 11, 1384-1393, doi: 10.1021/acsami.8b16920.

[73] X. Li, B. Y. Guan, S. Gao, X. W. Lou, Energy Environ. Sci., 2019, 12, 648-655, doi: 10.1039/C8EE02779J.

[74] Z.-Q. Liu, X.-T. Wang, T. Ouyang, L. Wang, J.-H. Zhong, Angew. Chem. Int. Ed., 2020, 59, 6492-6499, doi: 10.1002/anie.202000690.

[75] K. Hu, T. Szkopek, M. Cerruti, J. Mater. Chem. A, 2017, 5, 23123-23130, doi: 10.1039/C7TA07006C. 
[76] M. Chen, R. Guan, S. Yang, Adv. Sci., 2019, 6, 1800941, doi: 10.1002/advs.201800941.

[77] A. Song, L. Cao, W. Yang, W. Yang, L. Wang, Z. Ma, G. Shao, Carbon, 2019, 142, 40-50, doi: 10.1016/j.carbon.2018.09.088.

[78] R. Li, Z. Wei, X. Gou, ACS Catal., 2015, 5, 4133-4142, doi: 10.1021/acscatal.5b00601.

[79] J. Kim, S. H. Bae, M. Kotal, T. Stalbaum, K. J. Kim, I. K. Oh, Small, 2017, 13, 1701314, doi: 10.1002/smll.201701314.

[80] B. Y. Guan, L. Yu, X. W. D. Lou, Adv. Sci., 2017, 4, 1700247, doi: 10.1002/advs.201700247.

[81] W. Liu, R. Yin, X. Xu, L. Zhang, W. Shi, X. Cao, Adv. Sci., 2019, 6, 1802373, doi: 10.1002/advs.201802373.

[82] Q. Ren, H. Wang, X. F. Lu, Y. X. Tong, G. R. Li, Adv. Sci., 2018, 5, 1700515, doi: 10.1002/advs.201700515.

[83] H. Zhong, K. H. Ly, M. Wang, Y. Krupskaya, X. Han, J. Zhang, J. Zhang, V. Kataev, B. Buchner, I. M. Weidinger, S. Kaskel, P. Liu, M. Chen, R. Dong, X. Feng, Angew. Chem. Int. Ed., 2019, 58, 10677-10682, doi: 10.1002/anie.201907002.

[84] Y. Zheng, S. Zheng, H. Xue, H. Pang, Adv. Funct. Mater., 2018, 28, 1804950, doi: 10.1002/adfm.201804950.

[85] S. L. Zhang, B. Y. Guan, X. W. D. Lou, Small, 2019, 15, 1805324, doi: 10.1002/smll.201805324.

[86] W. Xie, Z. Li, S. Jiang, J. Li, M. Shao, M. Wei, Chem. Eng. J., 2019, 373, 734-743, doi: 10.1016/j.cej.2019.04.066.

[87] Z. Wang, J. Ang, J. Liu, X. Y. D. Ma, J. Kong, Y. Zhang, T. Yan, X. Lu, Appl. Catal. B: Environ., 2020, 263, 118344, doi: 10.1016/j.apcatb.2019.118344.

[88] J. Suntivich, H. A. Gasteiger, N. Yabuuchi, H. Nakanishi, J. B. Goodenough, Y. Shao-Horn, Nat. Chem., 2011, 3, 546-50, doi: 10.1038/nchem. 1069.

[89] J. Liu, M. Jiao, B. Mei, Y. Tong, Y. Li, M. Ruan, P. Song, G. Sun, L. Jiang, Y. Wang, Z. Jiang, L. Gu, Z. Zhou, W. Xu, Angew. Chem. Int. Ed., 2019, 58, 1163-1167, doi: 10.1002/anie. 201812423 .

[90] F. Cheng, J. Chen, Chem. Soc. Rev., 2012, 41, 2172-92, doi: 10.1039/c1cs15228a.

[91] H. Yang, K. Wang, Z. Tang, Z. Liu, S. Chen, J. Catal., 2020, 382, 181-191, doi: 10.1016/j.jcat.2019.12.018.

[92] S. Furukawa, T. Komatsu, ACS Catal., 2017, 7, 735-765, doi: 10.1021/acscatal.6b02603.

[93] S. A. Chala, M. C. Tsai, W. N. Su, K. B. Ibrahim, B. Thirumalraj, T. S. Chan, J. F. Lee, H. Dai, B. J. Hwang, ACS nano, 2020, 14, 1770-1782, doi: 10.1021/acsnano.9b07487.

[94] V. R. Stamenkovic, B. S. Mun, M. Arenz, K. J. Mayrhofer, C. A. Lucas, G. Wang, P. N. Ross, N. M. Markovic, Nat. Mater. 2007, 6, 241-7, doi: 10.1038/nmat1840.

[95] J. Greeley, I. E. Stephens, A. S. Bondarenko, T. P. Johansson, H. A. Hansen, T. F. Jaramillo, J. Rossmeisl, I. Chorkendorff, J. K. Norskov, Nat. Chem., 2009, 1, 552-6, doi: 10.1038/nchem.367.

[96] Z. Wang, X. Yao, Y. Kang, L. Miao, D. Xia, L. Gan, $A d v$. Funct. Mater, 2019, 29, 1902987, doi: 10.1002/adfm.201902987.

[97] C.-L. Lee, C.-C. Yang, C.-R. Liu, Z.-T. Liu, J.-S. Ye, J. Power Sources, 2014, 268, 712-717, doi: 10.1016/j.jpowsour.2014.06.112.

[98] S. Guo, S. Zhang, S. Sun, Angew. Chem. Int. Ed., 2013, 52, 8526-44, doi: 10.1002/anie.201207186.

[99] Z. Jiang, W. Sun, H. Shang, W. Chen, T. Sun, H. Li, J. Dong, J. Zhou, Z. Li, Y. Wang, R. Cao, R. Sarangi, Z. Yang, D. Wang, J. Zhang, Y. Li, Energy Environ. Sci., 2019, 12, 3508-3514, doi: 10.1039/c9ee02974e.

[100] W. Li, S. Xue, S. Watzele, S. Hou, J. Fichtner, A. L. Semrau, L. Zhou, A. Welle, A. S. Bandarenka, R. A. Fischer, Angew. Chem. Int. Ed., 2020, 59, 5837-5843, doi: 10.1002/anie.201916507.

[101] J.-J. Han, N. Li, T.-Y. Zhang, J. Power Sources, 2009, 193, 885-889, doi: 10.1016/j.jpowsour.2009.02.082.

[102] Y. Xu, B. Chen, J. Nie, G. Ma, Nanoscale, 2018, 10, 17021 17029, doi: 10.1039/c8nr02492h.

[103] J. Chen, X. Wang, X. Cui, G. Yang, W. Zheng, Chem. Commun., 2014, 50, 557-559, doi: 10.1039/c3cc47519k.

[104] S. M. Unni, S. N. Bhange, R. Illathvalappil, N. Mutneja, K. R. Patil, S. Kurungot, Small, 2015, 11, 352-360,doi: 10.1002/smll.201303892.

[105] T. Gong, R. Qi, X. Liu, H. Li, Y. Zhang, Nano-Micro Lett.,2019, 11, 9, doi: 10.1007/s40820-019-0240-x.

[106] S. Yi, X. Qin, C. Liang, J. Li, R. Rajagopalan, Z. Zhang, J. Song, Y. Tang, F. Cheng, H. Wang, M. Shao, Appl. Catal. B: Environ., 2020, 264, 118537, doi: 10.1016/j.apcatb.2019.118537. [107] K. Gong, F. Du, Z. Xia, M. Durstock, L. Dai, Science, 2009, 323, 760-764, doi: 10.1126/science.1168049.

[108] Y. Xu, P. Deng, G. Chen, J. Chen, Y. Yan, K. Qi, H. Liu, B. Y. Xia, Adv. Funct. Mater., 2019, 30, 1906081, doi: 10.1002/adfm.201906081.

[109] Q. Lv, N. Wang, W. Si, Z. Hou, X. Li, X. Wang, F. Zhao, Z. Yang, Y. Zhang, C. Huang, Appl. Catal. B: Environ., 2020, 261, 118234, doi: 10.1016/j.apcatb.2019.118234.

[110] H. Yu, L. Shang, T. Bian, R. Shi, G. I. Waterhouse, Y. Zhao, C. Zhou, L. Z. Wu, C. H. Tung, T. Zhang, Adv. Mater., 2016, 28, 5080-6, doi: 10.1002/adma.201600398.

[111]H. W. Liang, X. Zhuang, S. Bruller, X. Feng, K. Mullen, Nat. Commun, 2014, 5, 4973, doi: 10.1038/ncomms5973.

[112] J. Yang, H. Sun, H. Liang, H. Ji, L. Song, C. Gao, H. Xu, Adv. Mater, 2016, 28, 4606-13, doi: 10.1002/adma.201505855.

[113] H.-W. Liang, Z.-Y. Wu, L.-F. Chen, C. Li, S.-H. Yu, Nano Energy, 2015, 11, 366-376, doi: 10.1016/j.nanoen.2014.11.008.

[114] D. Guo, R. Shibuya, C. Akiba, S. Saji, T. Kondo, J. Nakamura, Science, 2016, 351, 361-365, doi: 10.1126/science.aad0832.

[115] L. Lai, J. R. Potts, D. Zhan, L. Wang, C. K. Poh, C. Tang, H. Gong, Z. Shen, J. Lin, R. S. Ruoff, Energy Environ. Sci., 2012, 5, 7936, doi: 10.1039/c2ee21802j.

[116] S. K. Singh, K. Takeyasu, J. Nakamura, Adv. Mater., 2019, 31, e1804297, doi: 10.1002/adma.201804297.

[117] L. Yang, J. Shui, L. Du, Y. Shao, J. Liu, L. Dai, Z. Hu, Adv. Mater., 2019, 31, 1804799, doi: 10.1002/adma.201804799.

[118] L. Dai, Y. Xue, L. Qu, H. J. Choi, J. B. Baek, Chem. Rev., 2015, 115, 4823-92, doi: 10.1021/cr5003563.

[119] Y. Zheng, Y. Jiao, L. Ge, M. Jaroniec, S. Z. Qiao, Angew. 
Chem. Int. Ed., 2013, 52, 3110-3116, 10.1002/anie.201209548.

[120] J. Zhu, W. Li, S. Li, J. Zhang, H. Zhou, C. Zhang, J. Zhang, S. Mu, Small, 2018, 14, e1800563, doi: 10.1002/smll.201800563. [121] M. M. Mohideen, Y. Liu, S. Ramakrishna, Appl. Energy, 2020, 257, 114027, doi: 10.1016/j.apenergy.2019.114027.

[122] J. Yang, F. Xiang, H. Guo, L. Wang, X. Niu, Carbon, 2020, 156, 514-522, doi: 10.1016/j.carbon.2019.09.087.

[123] B. Tang, J. Yang, Z. Kou, L. Xu, H. L. Seng, Y. Xie, A. D. Handoko, X. Liu, Z. W. Seh, H. Kawai, H. Gong, W. Yang, Energy Storage Mater, 2019, 23, 1-7, doi: 10.1016/j.ensm.2019.05.046.

[124] Y. L. Cao, H. X. Yang, X. P. Ai, L. F. Xiao, J. Electroanal. Chem., 2003, 557, 127-134, doi: 10.1016/s0022-0728(03)003553.

[125] T. Li, Y. Lu, S. Zhao, Z.-D. Gao, Y.-Y. Song, J. Mater Chem. $A, 2018$, 6, 3730-3737, doi: 10.1039/c7ta11171a.

[126] Y. Liang, Y. Li, H. Wang, J. Zhou, J. Wang, T. Regier, H. Dai, Nat. Mater., 2011, 10, 780-786, doi: 10.1038/nmat3087.

[127] J. Zhao, Y. He, Z. Chen, X. Zheng, X. Han, D. Rao, C. Zhong, W. Hu, Y. Deng, ACS Appl. Mater. Inter, 2018, 11, $4915-$ 4921, doi: 10.1021/acsami.8b16473.

[128] X. F. Lu, Y. Chen, S. Wang, S. Gao, X. W. Lou, Adv. Mater., 2019, 31, 1902339, doi: 10.1002/adma.201902339.

[129] X. Liu, L. Wang, P. Yu, C. Tian, F. Sun, J. Ma, W. Li, H. Fu, Angew. Chem. Int. Ed., 2018, 57, 16166-16170, doi: 10.1002/anie.201809009.

[130] Z. Guan, X. Zhang, W. Chen, J. Pei, D. Liu, Y. Xue, W. Zhu, Z. Zhuang, Chem. Commun., 2018, 54, 12073-12076, doi: $10.1039 / \mathrm{c} 8 \mathrm{cc} 05273 \mathrm{e}$.

[131] M. H. Seo, M. G. Park, D. U. Lee, X. Wang, W. Ahn, S. H. Noh, S. M. Choi, Z. P. Cano, B. Han, Z. Chen, Appl. Catal. B: Environ., 2018, 239, 677-687, doi: 10.1016/j.apcatb.2018.06.006.

[132] J. Wang, Z. Huang, W. Liu, C. Chang, H. Tang, Z. Li, W. Chen, C. Jia, T. Yao, S. Wei, Y. Wu, Y. Li, J. Am. Chem. Soc. 2017, 139, 17281-17284, doi: 10.1021/jacs.7b10385.

[133] X. Zhang, S. Zhang, Y. Yang, L. Wang, Z. Mu, H. Zhu, X. Zhu, H. Xing, H. Xia, B. Huang, J. Li, S. Guo, E. Wang, $A d v$ Mater, 2020, e1906905, doi: 10.1002/adma.201906905.

[134] H. Ji, M. Wang, S. Liu, H. Sun, J. Liu, T. Qian, C. Yan, Energy Storage Mater., 2020, 27, 226-231, doi: 10.1016/j.ensm.2020.02.002.

[135] C. Guan, A. Sumboja, H. Wu, W. Ren, X. Liu, H. Zhang, Z. Liu, C. Cheng, S. J. Pennycook, J. Wang, Adv. Mater., 2017, 29, 1704117, doi: 10.1002/adma.201704117.

[136] X. Zhong, W. Yi, Y. Qu, L. Zhang, H. Bai, Y. Zhu, J. Wan, S. Chen, M. Yang, L. Huang, M. Gu, H. Pan, B. Xu, Appl. Catal. B: Environ., 2020, 260, 118188, doi 10.1016/j.apcatb.2019.118188.

[137] R. Liu, D. Wu, X. Feng, K. Mullen, Angew. Chem. Int. Ed., 2010, 49, 2565-2569, doi: 10.1002/anie.200907289.

[138] Y. Lou, J. Liu, M. Liu, F. Wang, ACS Catal., 2020, $2443-$ 2451, doi: 10.1021/acscatal.9b03716.

[139] J. Kim, O. Gwon, O. Kwon, J. Mahmood, C. Kim, Y. Yang,
H. Lee, J. H. Lee, H. Y. Jeong, J. B. Baek, G. Kim, ACS nano, 2019, 13, 5502-5512, doi: 10.1021/acsnano.9b00320.

[140] T. Zhou, W. Xu, N. Zhang, Z. Du, C. Zhong, W. Yan, H. Ju, W. Chu, H. Jiang, C. Wu, Y. Xie, Adv. Mater., 2019, 31, e1807468, doi: 10.1002/adma.201807468.

[141] C. Zhang, J. Liu, Y. Ye, Q. Chen, C. Liang, Carbon, 2020, 156, 31-37, doi: 1016/j.carbon.2019.09.025.

[142] Y. Lv, L. Zhu, H. Xu, L. Yang, Z. Liu, D. Cheng, X. Cao, J. Yun, D. Cao, Eng. Sci., 2019, 7, 26-37. doi: 10.30919/es8d768. [143] M. Zhang, Q. Dai, H. Zheng, M. Chen, L. Dai, Adv. Mater., 2018, 30, doi: 10.1002/adma.201705431.

[144] C. Nita, M. Bensafia, C. Vaulot, L. Delmotte, C. Matei Ghimbeu, Carbon, 2016, 109, 227-238, doi: 10.1016/j.carbon.2016.08.011.

[145] Z. Wang, H. Jin, T. Meng, K. Liao, W. Meng, J. Yang, D. He, Y. Xiong, S. Mu, Adv. Funct. Mater., 2018, 28, 1802596, doi: 10.1002/adfm.201802596.

[146] X. Zhang, X. Han, Z. Jiang, J. Xu, L. Chen, Y. Xue, A. Nie, Z. Xie, Q. Kuang, L. Zheng, Nano. Energy., 2020, 71, 104547, doi: $10.1016 /$ j.nanoen.2020.104547.

[147] Z. K. Yang, L. Lin, A. W. Xu, Small, 2016, 12, 5710-5719, doi: 10.1002/smll.201601887.

[148] W. Yang, Y. Zhang, X. Liu, L. Chen, J. Jia, Chem. Commun., 2017, 53, 12934-12937, doi: 10.1039/c7cc08008e.

[149] X. Zhou, P. Wang, Y. Zhang, X. Zhang, Y. Jiang, ACS Sustain. Chem. Eng., 2016, 4, 5585-5593, doi: 10.1021/acssuschemeng.6b01408.

[150] X. Wang, S. Yun, W. Fang, C. Zhang, X. Liang, Z. Lei, Z. Liu, ACS Sustain. Chem. Eng., 2018, 6, 11397-11407, doi: 10.1021/acssuschemeng.8b01334.

[151] D. Wu, C. Zhu, Y. Shi, H. Jing, J. Hu, X. Song, D. Si, S. Liang, C. Hao, ACS Sustain. Chem. Eng., 2018, 7, 1137-1145, doi: 10.1021/acssuschemeng.8b04797.

[152] Z. Wang, D. Shen, C. Wu, S. Gu, Green Chem., 2018, 20, 5031-5057, doi: 10.1039/c8gc01748d.

[153] F. Zhou, Q. Liu, D. Kang, J. Gu, W. Zhang, D. Zhang, J. Mater. Chem. A, 2014, 2, 3505-3512, doi: 10.1039/c3ta14723a.

[154] Y. Gong, D. Li, C. Luo, Q. Fu, C. Pan, Green Chem., 2017, 19, 4132-4140, doi: 10.1039/c7gc01681f.

[155] T. Gao, C. Xu, R. Li, R. Zhang, B. Wang, X. Jiang, M. Hu, Y. Bando, D. Kong, P. Dai, X. B. Wang, ACS nano,2019, 13, 11901-11911, doi: 10.1021/acsnano.9b05978.

[156] Y.-C. Zhang, Y. You, S. Xin, Y.-X. Yin, J. Zhang, P. Wang, X.-S. Zheng, F.-F. Cao, Y.-G. Guo, Nano Energy, 2016, 25, 120 127, doi: 10.1016/j.nanoen.2016.04.043.

[157] Q. Niu, K. Gao, Q. Tang, L. Wang, L. Han, H. Fang, Y. Zhang, S. Wang, L. Wang, Carbon, 2017, 123, 290-298, doi: 10.1016/j.carbon.2017.07.078.

[158] B. Liu, Y. Liu, H. Chen, M. Yang, H. Li, J. Power Sources, 2017, 341, 309-317, doi: 10.1016/j.jpowsour.2016.12.022.

[159] H. Wu, J. Geng, H. Ge, Z. Guo, Y. Wang, G. Zheng, Adv. Energy Mater., 2016, 6, 1600794, doi: 10.1002/aenm.201600794. [160] X. Chen, L. Wei, Y. Wang, S. Zhai, Z. Chen, S. Tan, Z. Zhou, A. K. Ng, X. Liao, Y. Chen, Energy Storage Mater., 2018, 11, 134-143, doi: 10.1016/j.ensm.2017.10.011. 
[161] W. Wan, Q. Wang, L. Zhang, H-W. Liang, P. Chen, S-H. Yu, J. Mater. Chem. A, 2016, 4, 8602-8609, doi: 10.1039/C6TA02150F.

[162] H. J. Qiu, P. Du, K. Hu, J. Gao, H. Li, P. Liu, T. Ina, K. Ohara, Y. Ito, M. Chen, Adv. Mater., 2019, 31, 1900843, doi: 10.1002/adma.201900843.

[163] S. Song, W. Li, Y.-P. Deng, Y. Ruan, Y. Zhang, X. Qin, Z. Chen, Nano Energy, 2020, 67, 104208, doi: 10.1016/j.nanoen.2019.104208.

[164] Y. Liu, F. Chen, W. Ye, M. Zeng, N. Han, F. Zhao, X. Wang, Y. Li, Adv. Funct. Mater, 2017, 27, 1606034, doi: 10.1002/adfm.201606034

[165] Q. Zhou, Z. Zhang, J. Cai, B. Liu, Y. Zhang, X. Gong, X. Sui, A. Yu, L. Zhao, Z. Wang, Z. Chen, Nano Energy, 2020, 71, 104592, doi: 10.1016/j.nanoen.2020.104592.

[166] B. Chen, X. He, F. Yin, H. Wang, D.-J. Liu, R. Shi, J. Chen, H. Yin, Adv. Funct. Mater., 2017, 27, 1700795, doi: 10.1002/adfm.201700795.

[167] Shuang Li, Chong Chen, Xiaojia Zhao, Johannes Schmidt, Arne Thomas, Angew. Chem. Int. Ed., 2018, 57, 1856-1862, doi: 10.1002/anie.201710852.

[168] K. He, J. Zai, X. Liu, Y. Zhu, A. Iqbal, T. Tadesse Tsega, Y. Zhang, N. Ali, X. Qian, Appl. Catal. B: Environ., 2020, 265, 118594, doi: 10.1016/j.apcatb.2020.118594.

[169] J.-C. Li, P.-X. Hou, M. Cheng, C. Liu, H.-M. Cheng, M. Shao, Carbon, 2018, 139, 156-163, doi: 10.1016/j.carbon.2018.06.023.

[170] Li Song, Tao Wang, Linghui Li, Chao Wu, Jianping He, Appl. Catal. B: Environ., 2019, 244, 197-205, doi: 10.1016/j.apcatb.2018.11.005.

[171] D. Liu, B. Wang, H. Li, S. Huang, M. Liu, J. Wang, Q. Wang, J. Zhang, Y. Zhao, Nano Energy, 2019, 58, 277-283, doi: 10.1016/j.nanoen.2019.01.011.

\section{Author information}

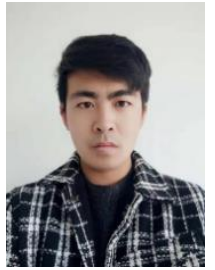

Junkai Zhao received the B.S. degree in 2016 from Qilu University of Technology (Shandong Academy of Sciences) and the M.S. degree in 2019 from Shandong University of Science and Technology, respectively. He is currently a Ph.D. candidate at the college of chemistry, Beijing Normal University in the group of Professor Xiaojing Yang and jointly trained in Dr. Ce Zhang's group in Qian Xuesen Laboratory of Space Technology, China Academy of Space Technology. His current research focuses on the active materials and electrolytes for lithium-ion batteries and all solid-state batteries.

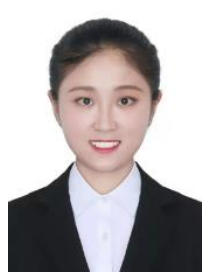

Daina Wei is currently a M.D. student at the college of chemistry, Beijing Normal University in the group of Professor Xiaojing Yang and jointly trained in Dr. Ce Zhang's group in Qian Xuesen Laboratory of Space Technology, China Academy of Space
Technology. She received her B.S. degree (2019) in the college of teacher education, Nanjing Normal University, China. Her present research interest is advanced anode materials for next generation lithium-ion batteries.

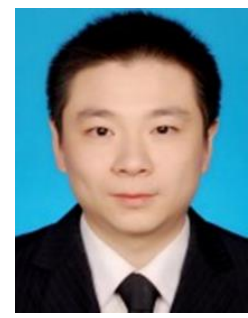

Ce Zhang is a tenure-track research fellow in Qian Xuesen Laboratory of Space Technology, China Academy of Space Technology. He received his Ph.D. degree in 2014 from Yokohama National University Japan and joined Qian Xuesen Laboratory in 2015. His current research interests are energy conversion and storage materials and corresponding technologies, such as all-solid lithium batteries, extraterrestrial artificial photosynthesis (EAP) and in-situ resource utilization (ISRU) technology.

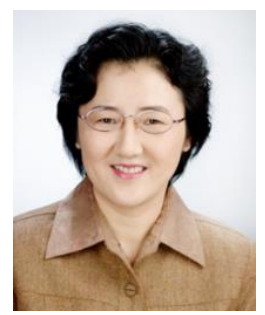

Qian Shao, Professor of College of Chemical and Biological Engineering, Shandong University of Science and Technology. Her main research interest are advanced inorganic nanomaterials and waterborne resins for photocatalysts, adsorbents and corrosion inhibitor.

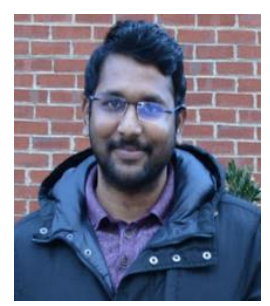

Vignesh Murugadoss obtained his Ph.D. degree from the Centre for Nanoscience and Technology at Pondicherry University, Puducherry. He carried out the Indo-US BASE internship at Integrated Composites Laboratory, Department of Chemical and Biomolecular Engineering at the University of Tennessee, Knoxville, USA. His research interests focus on advanced functional materials for sustainable energy and environmental applications.

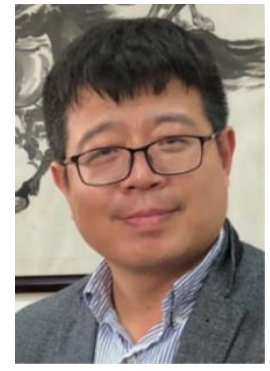

Zhanhu Guo earned his Ph.D. degree in chemical engineering from Louisiana State University in 2005. He received his threeyear postdoctoral training in mechanical and aerospace engineering at the University of California Los Angeles. He is a Professor in Chemical and Biomolecular Engineering directs the Integrated Composites Laboratory at The University of Tennessee, Knoxville. His current research interests are in the areas of optoelectronic, electric, and magnetic materials for solar cells, catalysis, sensing, and electronics.

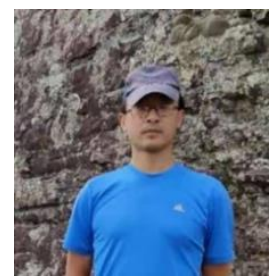
Qinglong Jiang is an Assistant Professor (Tenure Track) in the Department of Chemistry and Physics in University of Arkansas, Pine Bluff. Prior to joining in $U A P B$, he worked in Argonne National Lab after his postdoc researcher career in 
Florida State University. His research focuses on nanomaterials and technologies for electric-optical devices, such as halide perovskite for solar cell and light emitting, dye sensitive solar cell, electrochromism, sensors, fluorescence and etc.

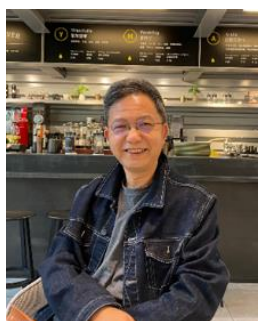

Xiaojing Yang is a Professor in Beijing Normal University (China). He received his Ph.D. degree in 1992 from Shanghai institute of ceramics. After five-year working as a researcher in Japan, he joined Beijing Normal University in 2006.

His research activities are focused on inorganic materials chemistry and electrochemical energy storage.
Publisher's Note: Engineered Science Publisher remains neutral with regard to jurisdictional claims in published maps and institutional affiliations. 